\title{
The added value of a visible channel to a geostationary thermal infrared instrument to monitor ozone for air quality
}

\author{
E. Hache ${ }^{1,2}$, J.-L. Attié ${ }^{1,2}$, C. Tourneur ${ }^{3}$, P. Ricaud ${ }^{1}$, L. Coret $^{3}$, W. A. Lahoz $^{4}$, L. El Amraoui ${ }^{1}$, B. Josse ${ }^{1}$, P. Hamer ${ }^{1}$,

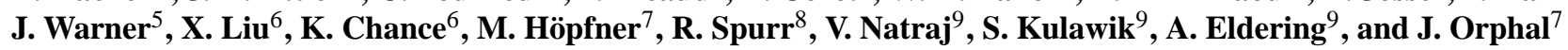 \\ ${ }^{1}$ GAME/CNRM, Météo-France, UMR3589, CNRS, Toulouse, France \\ ${ }^{2}$ Université de Toulouse, CNRS, Laboratoire d'Aérologie, Toulouse, France \\ ${ }^{3}$ EADS Astrium, Toulouse, France \\ ${ }^{4}$ NILU - Norwegian Institute for Air Research, 2027, Kjeller, Norway \\ ${ }^{5}$ The University of Maryland, College Park, MD 20742, USA \\ ${ }^{6}$ Harvard-Smithsonian Center for Astrophysics, Cambridge, MA 02138, USA \\ ${ }^{7}$ Karlsruhe Institute of Technology, IMK, Karlsruhe, Germany \\ ${ }^{8}$ RT Solutions, Inc. 9 Channing Street, Cambridge, MA 02138, USA \\ ${ }^{9}$ Jet Propulsion Laboratory (NASA-JPL), 4800 Oak Grove Drive, Pasadena, CA 91109, USA
}

Correspondence to: E. Hache (emeric.hache@meteo.fr)

Received: 20 December 2013 - Published in Atmos. Meas. Tech. Discuss.: 17 February 2014

Revised: 3 June 2014 - Accepted: 11 June 2014 - Published: 22 July 2014

\begin{abstract}
Ozone is a tropospheric pollutant and plays a key role in determining the air quality that affects human wellbeing. In this study, we compare the capability of two hypothetical grating spectrometers onboard a geostationary (GEO) satellite to sense ozone in the lowermost troposphere (surface and the $0-1 \mathrm{~km}$ column). We consider 1 week during the Northern Hemisphere summer simulated by a chemical transport model, and use the two GEO instrument configurations to measure ozone concentration (1) in the thermal infrared (GEO TIR) and (2) in the thermal infrared and the visible (GEO TIR+VIS). These configurations are compared against each other, and also against an ozone reference state and a priori ozone information. In a first approximation, we assume clear sky conditions neglecting the influence of aerosols and clouds. A number of statistical tests are used to assess the performance of the two GEO configurations. We consider land and sea pixels and whether differences between the two in the performance are significant. Results show that the GEO TIR+VIS configuration provides a better representation of the ozone field both for surface ozone and the 0 $1 \mathrm{~km}$ ozone column during the daytime especially over land.
\end{abstract}

\section{Introduction}

Air quality (AQ) is by definition related to the concentration of chemical pollutants in the atmosphere close to the Earth's surface. Air quality varies dynamically over space and time (McNair et al., 1996) due to different processes. These include chemistry, transport (both short- and longrange transport, and turbulence in the boundary layer), and local sources of pollutants, both biogenic and anthropogenic. Key lower-tropospheric pollutants include ozone, aerosols (e.g. particulate matter, PM), and the ozone precursors like nitrogen oxides, volatile organic compounds (VOCs) and carbon monoxide. Tropospheric ozone controls the oxidation of many chemical species through reactions involving the hydroxyl radical, OH (Holloway and Wayne, 2010; Brasseur et al., 2003); and tropospheric ozone follows a diurnal cycle (minimum in the early morning and maximum in the afternoon) due to the photo-chemical reactions between the nitrogen oxides and VOCs that produce ozone during the daytime.

Air quality impacts human society: pollution at the Earth's surface causes health problems, including pulmonary and cardiovascular diseases (Brunekreef and Holgate, 2002), and recognition is growing of the combined health effects of multiple pollutants (Dominici et al., 2010). Air quality is also 
dependent on the interactions between human societal factors and certain episodic weather events. For example: during summer heat waves, the temperature coupled with the anthropogenic and biogenic ozone precursor emissions can produce ozone pollution over cities and megacities; during winter episodes, the extensive wood burning due to heating results in PM pollution. The annual health costs attributable to AQ in 2020 are predicted to range between EUR 188 billion and 608 billion (see http://ec.europa.eu/smart-regulation/impact/ ia_carried_out/docs/ia_2005/sec_2005_1133_en.pdf) due to the resulting health damage (mortality and morbidity) in the EU-25 countries. This significant cost explains why governments are increasingly concerned about AQ. Legislation designed to address AQ is becoming increasingly common. Many of these new laws seek to introduce thresholds and limitations upon pollutant concentrations to protect human health (for example the European directive 2008/50/CE). This legislation relating to AQ is typically accompanied by projects designed to monitor and forecast pollutant abundances.

In order to monitor, forecast and manage AQ, observations are needed at a high spatio-temporal resolution that can capture the variability in the lowermost troposphere of either pollutants or their precursors. Such observations can be useful directly and may also improve understanding of emissions, chemical transformations, and transport from urban to intercontinental scales. Appropriate temporal and spatial resolutions for observations are (Lahoz et al., 2012): (i) temporal sampling less than $1 \mathrm{~h}$, and (ii) spatial scales less than $\sim 10 \mathrm{~km}$. Local contributions to AQ are well sampled by surface networks. However, the surface network lacks sufficient spatial coverage and height resolved information, in particular, in the planetary boundary layer (IGACO, 2004), to fully capture the regional and continental-scale AQ picture. Spaceborne observations at sufficient spatial resolution represent a suitable means of gaining this increase in coverage (Fishman et al., 2008; Martin, 2008). Many low Earth orbit (LEO) satellites measure pollutant species in the lower troposphere (see Lahoz et al., 2012, for a list of some of these satellite missions), but as indicated in Lahoz et al. (2012), the LEO geometry is less satisfactory than the geostationary (GEO) satellite geometry for monitoring AQ at the appropriate spatio-temporal resolutions (see above).

In the near future, the global observing system regarding the monitoring of AQ will be improved by a number of initiatives that are planning GEO satellite missions to monitor chemical species. In Europe, for example, the GMES (Global Monitoring of Environment and Security) Sentinel4 UVN (Ultraviolet, Visible, Near-infrared) platform (ESA, 2007) will measure tropospheric $\mathrm{O}_{3}, \mathrm{NO}_{2}, \mathrm{HCHO}, \mathrm{SO}_{2}$ and aerosol properties (column-averaged optical thickness and aerosol type), and the Meteosat Third Generation infrared sounder (MTG IRS) platform (Munro, 2011) will be able to measure tropospheric $\mathrm{O}_{3}$ and $\mathrm{CO}$ (although as a numerical weather prediction sounder, it is not optimized for these species). The Sentinel-4 UVN and MTG IRS instruments are due for launch from 2017/18 onwards. A number of projects outside Europe are also developing GEO satellites for chemical species monitoring. These include the NASA TEMPO (Tropospheric Emissions: Monitoring of POllution) mission with proposed launch in 2018/19 (Chance et al., 2013), the NASA GEO-CAPE mission (GEOstationary Coastal and Air Pollution Events) with a proposed launch in the 2020 time frame, and the Korean GEO-KOMPSAT (Geostationary Korea Multi-Purpose Satellite) mission, with a planned launch in 2017/18 (Lee et al., 2010). These developments in Europe, the United States, and Asia focus on tropospheric aerosols and trace gases such as ozone. Synergies between European, the United States, and Asian GEO satellite platforms would be of great benefit for the quasi-global monitoring of AQ (CEOS, 2011). Synergy between GEO and LEO satellite platforms and surface observations would provide further benefits.

Previous studies have shown the potential advantages of GEOs to monitor AQ, and in particular that they provide a good compromise between spatiotemporal resolution and spatial coverage (e.g. Burrows et al., 2004; Orphal et al., 2005; Zoogman et al., 2011). It is recognized that a multispectral approach is required to monitor AQ in the lowermost troposphere from a GEO (Lahoz et al., 2012; Natraj et al., 2011). To understand this requirement, a number of $A Q$ studies have considered thermal infrared (TIR) instruments (e.g. Claeyman et al., 2011b), ultraviolet/visible (UV/VIS) instruments (e.g. Liu et al., 2005), and instrument combinations thereof (e.g. Landgraf and Hasekamp, 2007; Worden et al., 2007; Natraj et al., 2011; Cuesta et al., 2013; Fu et al., 2013). In this paper, we build on the study of Claeyman et al. (2011b) and consider the capabilities of the proposed MAGEAQ (Monitoring the Atmosphere from Geostationary orbit for European Air Quality) GEO mission that aimed to use thermal infrared (TIR) and visible (VIS) instruments onboard the same satellite (Peuch et al., 2009) to monitor ozone in the lowermost troposphere (surface and the $0-1 \mathrm{~km}$ height region) for AQ purposes.

In this study, we quantify the improvement in ozone measurement capability in the lowermost troposphere when using an instrument that combines the TIR+VIS (GEO TIR+VIS) channels compared to an instrument that uses only the TIR (GEO TIR) channel. This will be done using the observing system simulation experiment (OSSE) approach (e.g. Masutani et al., 2010) in which a reference state is set up and sampled to simulate the ozone as seen by the GEO TIR and GEO TIR+VIS configurations. We then compare both sets of retrievals to the reference state. In our study, the reference state is simulated with the chemical transport model MOCAGE (MOdèle de Chimie Atmosphérique à Grande Echelle) (see Sect. 2.1). We are interested in whether the GEO TIR+VIS ozone retrievals are closer than the GEO TIR ozone retrievals to the reference state. One difference between our approach and the standard OSSE method is that 
we do not perform data assimilation to produce ozone fields to compare against the reference state; instead, we perform retrievals to produce ozone fields to be compared against the reference state.

In Sect. 2, we present the tools developed to calculate ozone retrievals using the simulated radiances of the GEO TIR and GEO TIR+VIS instruments. Section 3 discusses the comparison between the GEO TIR and GEO TIR+VIS simulated ozone retrievals against the reference state for a period of 1 week during an European summer. Section 4 presents conclusions and perspectives from this work.

\section{Simulated observations and reference state}

We use a chemical-transport model (CTM) to simulate the reference state for ozone. This ozone field is then used as input into a radiative transfer model (RTM) incorporating the instrument model specifications to represent radiances measured by the instrument. In a second step, an inversion model (optimal estimation) is used to transform the radiances measured by the instrument into an ozone profile. This allows us to derive simulated data of ozone which are then compared to the fields of ozone from the reference state. The various tools in this process of simulation and retrieval are described in Sects. 2.1-2.5.

\subsection{Chemical transport model}

The CTM used in this study is MOCAGE (MOdèle de Chimie Atmosphérique à Grande Echelle). MOCAGE is a three-dimensional CTM that simulates the physical and chemical processes affecting the main chemical species in the troposphere and the stratosphere (Bousserez et al., 2007). It uses a semi-Lagrangian advection scheme (Josse et al., 2004) to transport the chemical species. Turbulent diffusion is calculated with the scheme of Louis (1979) and convection is processed with the parameterization scheme of Bechtold et al. (2001). The chemical scheme used in this study is RACMOBUS, which is a combination of the stratospheric chemical scheme REPROBUS (Lefevre et al., 1994) and the tropospheric chemical scheme RACM (Stockwell et al., 1997). It includes 119 individual species with 89 prognostic variables and 372 chemical reactions. The version of MOCAGE used in our study has a vertical resolution of 47 hybrid levels from the surface up to $5 \mathrm{hPa}$, with a resolution of about $150 \mathrm{~m}$ in the lower troposphere increasing to $800 \mathrm{~m}$ in the upper troposphere. In this study, the horizontal grid uses two different nested latitude-longitude domains, the first at $2^{\circ}$ over the globe and the second at $0.5^{\circ}$ over Europe. MOCAGE uses the ARPEGE meteorological analyses, from Météo-France, to force the model every $3 \mathrm{~h}$. The emission inventory used is that provided by TNO (Netherlands Organization for Applied Scientific Research). MOCAGE is used, and has been validated, in the Global and regional Earth-system Monitoring using Satellite and in situ data (GEMS) project (Hollingsworth et al., 2008) and in the MACC (Monitoring atmospheric composition and climate) project (http://www.gmes-atmosphere.eu/about/project/).

\subsection{Radiative transfer models}

We focus on the ozone signature present in the TIR and VIS (the Chappuis bands). TIR provides sensitivity to ozone in the middle troposphere during daytime and night-time whereas the VIS provides sensitivity to ozone close to the surface only during daytime (Natraj et al., 2011). We couple two different RTMs to simulate the radiances seen by a geostationary satellite grating spectrometer instrument in the TIR and VIS. Ozone in the TIR has already been measured by several LEOs with sensitivity in the mid-troposphere, e.g. the Infrared Atmospheric Sounding Interferometer (IASI), see, for example Clerbaux et al. (2009), sampling the lowermost troposphere in the TIR+UV combining both IASI (TIR) and GOME-2 (UV) (Cuesta et al., 2013) or both TES (Tropospheric Emission Spectrometer) and OMI (Ozone Monitoring Instrument) (Fu et al., 2013). The advantage of measuring in the VIS is to have ozone information at the Earth's surface for monitoring the AQ. The two RTMs are briefly described below.

The first one, KOPRA (Karlsruhe Optimized and Precise Radiative transfer Algorithm, Höpfner et al., 1998; Stiller et al., 2002), is used to simulate the TIR part of the radiances for both GEO TIR and GEO TIR+VIS. KOPRA was developed by the Karlsruhe Institute of Technology (KIT) in 1998 (http://www.imk-asf.kit.edu/english/312.php). It was primarily designed to simulate atmospheric radiative transfer in the infrared for the MIPAS/ENVISAT satellite mission (Fischer et al., 2008; Carli et al., 2012). KOPRA is a lineby-line RTM and uses the HITRAN spectroscopic database (Rothman et al., 2005, 2009). KOPRA has been validated for nadir geometry by Tjemkes et al. (2003).

We couple KOPRA with the VLIDORT (Vector LInearized Discrete Ordinate Radiative Transfer) model (Spurr, 2006), the latter being used to simulate the VIS part of the radiances for GEO TIR+VIS. VLIDORT is a monochromatic multiple scattering RTM; it deals with polarized light scattering, and it uses the pseudo-spherical approximation for treating solar-beam attenuation in a curved atmosphere. VLIDORT is able to generate simultaneous fields of Jacobians (weighting functions) of simulated Stokes four vectors with respect to any profile of atmospheric variables and/or any surface parameter (Spurr, 2008).

Our forward model assumes a Lambertian surface, with the spectral database of reflectivity coming from the GOME (Global Ozone Monitoring Experiment) instrument (Koelemeijer et al., 2003). Cross sections are either derived from line-by-line spectroscopy based on the HITRAN 2004 and 2008 database (Rothman et al., 2005, 2009), or taken from a UV/visible trace-species database (Daumont et al., 1992; 
Brion et al., 1993, 1998; Malicet et al., 1995) used for the GEOCAPE simulations (Natraj et al., 2011). In a first approximation, we do not take into account clouds or aerosols, treating only Rayleigh scattering and trace gas absorption in the visible - these are our "clear-sky" conditions.

\subsection{Inverse method}

The optimal estimation inversion scheme used in this study is the iterative Newton-Raphson scheme which is suitable for non-linear problems. The Levenberg-Marquardt algorithm (Marquardt, 1963) is incorporated into this method to reduce instability during the inversion. More details can be found in Rodgers (2000).

The equation for the inversion method is

$$
\begin{aligned}
\boldsymbol{x}_{i+1}= & \boldsymbol{x}_{\mathrm{a}}+\left(\mathbf{K}_{i}^{\mathrm{t}} \cdot \mathbf{S}_{y}^{-1} \cdot \mathbf{K}_{i}+(1+\gamma) \cdot \mathbf{S}_{\mathrm{a}}^{-1}\right)^{-1} \\
& \times\left[\mathbf{K}_{i}^{\mathrm{t}} \cdot \mathbf{S}_{y}^{-1} \cdot\left(\left[\boldsymbol{y}-F\left[\boldsymbol{x}_{i}\right]\right]+\mathbf{K}_{i} \cdot\left[\boldsymbol{x}_{i}-\boldsymbol{x}_{\mathrm{a}}\right]\right)\right. \\
& \left.+\gamma \cdot \mathbf{S}_{\mathrm{a}}^{-1} \cdot\left[\boldsymbol{x}_{i}-\boldsymbol{x}_{\mathrm{a}}\right]\right]
\end{aligned}
$$

where $\boldsymbol{x}_{i}$ is the estimate of the state vector at iteration $i ; \boldsymbol{x}_{\mathrm{a}}$ is the a priori state vector (see Sect. 2.4); $F\left[\boldsymbol{x}_{i}\right]$ is the radiance calculated by the RTM from $\boldsymbol{x}_{i} ; \boldsymbol{y}$ is the radiance measured by the instrument; $\mathbf{K}_{i}$ is the Jacobian matrix of the radiance over $\boldsymbol{x}\left(\mathbf{K}=\frac{\partial F[x]}{\partial \boldsymbol{x}}\right) . \mathbf{S}_{\mathrm{a}}^{-1}$ is the inverse of the error covariance matrix of the a priori. $\mathbf{S}_{y}^{-1}$ is the inverse of the error covariance matrix of the measurements. Finally, $\gamma$ is the Levenberg-Marquardt parameter. This parameter is adjusted at each iteration to minimize the cost function. At iteration 0 , the inversion starts with $\gamma=1$ and the estimate of the state vector at iteration 0 is $\boldsymbol{x}_{0}=\boldsymbol{x}_{\mathrm{a}}$. A $\chi^{2}$ test determines how $\gamma$ is adjusted. If the $\chi^{2}$ value calculated at iteration $i$ decreases, we reduce by a factor of 5 the value of $\gamma$, and we go to iteration $i+1$. However, if the $\chi^{2}$ value increases, we increase by a factor of 5 the value of $\gamma$ and we repeat iteration $i$. The calculation stops after 10 iterations, or if the value of $\gamma$ is consecutively increased five times and is not able to reduce the $\chi^{2}$ value.

\subsection{A priori information}

As indicated in Eq. (1), a priori information is needed to retrieve the state vector. In this study, the focus is on the retrieval of ozone and on the main parameters that can affect this retrieval: the $\mathrm{H}_{2} \mathrm{O}$ profile, the temperature profile and the surface albedo. The a priori information related to $\mathrm{H}_{2} \mathrm{O}$ and temperature profiles and surface albedo is assumed to come from measurements made by other satellite instruments or from meteorological analysis/prediction. In this study, the a priori data are simulated by adding a random value to the reference state to introduce a small error. The reference state is simulated with the MOCAGE CTM described in Sect. 2.1. Thus we assume $x_{\mathrm{a}}=x_{\mathrm{rs}}+\epsilon_{\mathrm{rs}}$, where $x_{\mathrm{a}}$ is the a priori value of the parameter; $x_{\mathrm{rs}}$ is the reference state value of
Table 1. Summary of the instrument configurations used.

\begin{tabular}{|c|c|}
\hline \multicolumn{2}{|l|}{ Configuration } \\
\hline Field of regard & $15^{\circ} \mathrm{W}-35^{\circ} \mathrm{E}, 35-65^{\circ} \mathrm{N}$ \\
\hline Repeat cycle & $1 \mathrm{~h}$ \\
\hline Spatial resolution over Europe & $15 \mathrm{~km} \times 15 \mathrm{~km}$ \\
\hline \multicolumn{2}{|l|}{ TIR channel } \\
\hline Spectral band & $1000-1070 \mathrm{~cm}^{-1}$ \\
\hline Spectral sampling resolution & $0.1 \mathrm{~cm}^{-1}$ \\
\hline Spectral resolution FWHM & $0.2 \mathrm{~cm}^{-1}$ \\
\hline NESR & $6.04 \mathrm{nW}\left(\mathrm{cm}^{2} \mathrm{sr} \mathrm{cm}^{-1}\right)^{-1}$ \\
\hline \multicolumn{2}{|l|}{ VIS channel } \\
\hline Spectral band & $520-650 \mathrm{~nm}$ \\
\hline Spectral sampling resolution & $0.3 \mathrm{~nm}$ \\
\hline Spectral resolution FWHM & $1.2 \mathrm{~nm}$ \\
\hline NESR & $9.2 \times 10^{-3} \mathrm{~W}\left(\mathrm{~m}^{2} \mathrm{sr} \mathrm{nm}\right)^{-1}$ \\
\hline
\end{tabular}
TIR $=$ thermal infrared; VIS = visible; FWHM = full width half maximum; NESR $=$ noise equivalent source radiance.

the parameter; and $\epsilon_{\mathrm{rs}}$ is a random Gaussian value with mean 0 and a standard deviation $\sigma_{\mathrm{rs}}$. As done in Claeyman et al. (2011b), we assume for the $\mathrm{H}_{2} \mathrm{O}$ profiles a $\sigma_{\mathrm{rs}}$ of $10 \%$ at each pressure level, and for the temperature profile a $\sigma_{\mathrm{rs}}$ of $1 \mathrm{~K}$ at each pressure level. The surface albedo comes from a spectral database of reflectivity over the globe which provides for pixels of $1^{\circ}$ the value of the reflectivity at $335,380,416,440$, $463,494,555,610,670,758$ and $772 \mathrm{~nm}$. These reflectivities are fitted with third-order polynomials which are used in the VLIDORT calculations and in the inversion method. We retrieve the four coefficients of the polynomial function simultaneously with the other parameters. For the a priori on the albedo, we use the four coefficients obtained with the polynomial fit of the reflectivity database, and we then attach an error on each coefficient, in order to have a relative error of $10 \%$ on the albedo.

The ozone a priori is calculated as the average of all ozone profiles from the MOCAGE CTM over Europe between 1 July 2008 and 31 August 2008, a period different to that considered for the comparison between GEO TIR and GEO TIR+VIS ( 9 to 15 July 2009). Thus, the $\mathrm{O}_{3}$ a priori is constant for all retrievals. This makes it easier to do the comparison between the different satellite configurations, which is done by studying the variability of the retrieved observations. A future possible improvement of this work would be to use dynamic $\mathrm{O}_{3}$ a priori profiles that vary over Europe and over time.

\subsection{Instrument model}

The instrument simulator models a grating spectrometer onboard a geostationary satellite. It calculates the radiance with instrumental noise using the two RTMs. The RTMs take into 
account the instrument geometry (i.e. an instrument onboard a geostationary satellite focused over Europe, at an altitude of $36000 \mathrm{~km}$, and positioned at $0^{\circ}$ latitude and $10^{\circ}$ longitude) to calculate the radiance that reaches the instrument. The purpose of the instrument model is to take into account the wavelength bands of the instrument, the spectral resolution of each band and the measurement noise (see Table 1). The radiance output of the RTM is convolved with a Gaussian slit function to simulate the spectral spread of the instrument. A filter is applied to this radiance to fit the spectral TIR and VIS transmission bands of the instrument. In each band, the radiance is discretized to be consistent with the spectral sampling resolution. To take into account the instrumental noise, we add to this radiance (called $\boldsymbol{I}_{\text {mod }}$ in Eq. 2) a value which depends on the signal-to-noise ratio (SNR) and a random number following the standard normal distribution $(\tilde{N})$. The final measured radiance is

$\boldsymbol{I}_{\text {meas }}=\boldsymbol{I}_{\text {mod }}+\left(\frac{\boldsymbol{I}_{\text {mod }}}{\boldsymbol{\sigma}_{\mathrm{SNR}}} \times \tilde{\boldsymbol{N}}\right)$.

Moreover, we assume that, for a grating spectrometer, the SNR varies with the wavelength $\lambda$ using the formula $\sigma_{\mathrm{SNR}}(\lambda)=a \times \lambda+b$, where $\lambda$ is in nm, $a$ and $b$ are the coefficients derived from the detailed MAGEAQ concept study made by the industrial consortium ASTRIUM/AIRBUS. This simplified model accounts for the various noise contributors, including shot noise and also dark current, read out, flicker, thermal and quantization noises amongst the most significant technological noises. This study takes into account the different optical materials, focal planes, viewing geometry and integration time of two grating spectrometers (TIR and VIS). Claeyman et al. (2011b) already described the TIR configuration and Fig. 1 presents the calibration curve showing the variation of SNR vs. the wavelength for the VIS grating spectrometer. The SNR of the typical radiance case used in this study and the minimal radiance case are also presented in this figure.

To obtain the maximum sensitivity of our instrument to surface ozone, we take into account the information provided by the TIR and VIS bands. A compromise has to be made between the choice and the number of the spectral bands, the total bandwidth, the spectral resolution of the instrument in each band, and the technology and final cost of the instrument. In this study, we choose a feasible instrument configuration that optimizes high-quality surface ozone retrievals (see Table 1). This configuration is based on the MAGEAQ concept which was proposed to the EE8 ESA call (Peuch et al., 2010). The instrument presented in our study uses two combined grating spectrometers, one with a spectral band in the TIR, and the other one with a spectral band in the VIS. The characteristics of these two bands are as follows: The TIR band has 21 micro-windows between 1000 and $1070 \mathrm{~cm}^{-1}$, a spectral sampling resolution of $0.1 \mathrm{~cm}^{-1}$, and a spectral resolution of $0.2 \mathrm{~cm}^{-1}$ full width at half maximum (FWHM) of the Gaussian slit function. The coefficients for

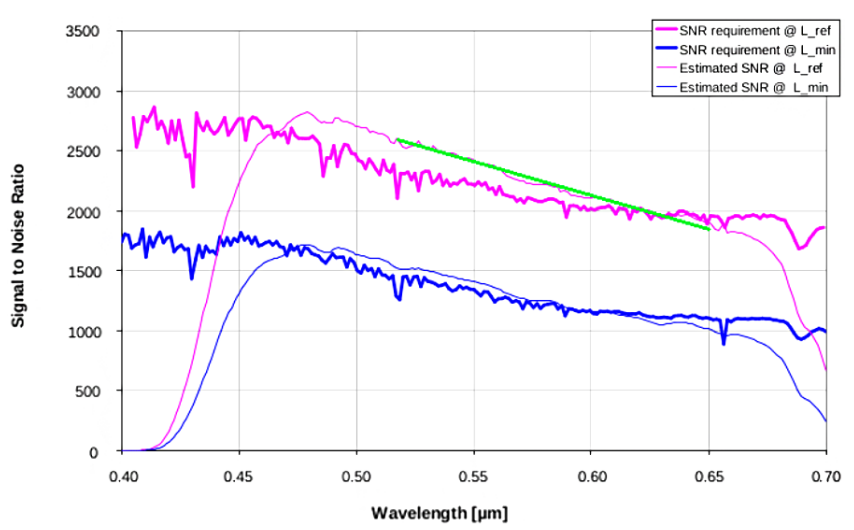

Figure 1. Calibration curves representing the variation of the SNR with respect to the wavelength for the MAGEAQ VIS instrument. The pink lines indicate the SNR for the typical radiance case (L_ref) and the blue lines indicate the SNR for the minimal radiance case (L_min). The thick lines show the SNR requirement and the thin lines show the SNR estimated for the instrument. The thin pink curve is fitted by a linear line (green line) to derive the instrument noise model.

the noise model are: $a=-1.374\left(\mathrm{~nm}^{-1}\right)$ and $b=13940.0$ (dimensionless). This represents, on average, a noise equivalent source radiance (NESR) of $6.04 \mathrm{nW}\left(\mathrm{cm}^{2} \mathrm{sr} \mathrm{cm}^{-1}\right)^{-1}$. The VIS band has one micro-window from 520 to $650 \mathrm{~nm}$ inside the Chappuis band, a spectral sampling resolution of $0.3 \mathrm{~nm}$, and a spectral resolution of $1.2 \mathrm{~nm}$ FWHM. The coefficients for the noise model are: $a=-5.83\left(\mathrm{~nm}^{-1}\right)$ and $b=5616.0$ (dimensionless) (see Fig. 1). This represents, on average, a NESR of $9.2 \times 10^{-3} \mathrm{~W}\left(\mathrm{~m}^{2} \mathrm{sr} \mathrm{nm}\right)^{-1}$.

Concerning the polarization of the light associated with the instrument measurement, the first assumption, usually accepted, is to neglect the circular component in the atmosphere (e.g. Schutgens and Stammes, 2003). Furthermore, it is possible to add a scrambler device in the instrument design, which reduces the polarization effects. In other words, the linear components of the polarization of the light can be neglected with this instrumental improvement (Laan et al., 2000).

Like MAGEAQ, the GEO TIR and GEO TIR+VIS instruments are designed to measure hourly ozone over Europe, with a pixel size of $15 \mathrm{~km} \times 15 \mathrm{~km}$ at $45^{\circ}$ latitude. Figure 2 shows an ozone field simulated with the field of view (FOV) of the GEO instruments. In this study, we use a smaller domain over the western part of Europe from the FOV of the instrument and we degrade the spatial resolution to $0.5^{\circ} \times 0.5^{\circ}$ for each pixel to fit the MOCAGE CTM grid (see Fig. 2). This change in the instrumental configuration has no impact on our study that focuses on the comparison between GEO TIR and GEO TIR+VIS for which we have used the same spatial resolution. Degrading the horizontal resolution and the domain under investigation is a direct consequence of the high computation time needed to simulate the instrument 
Table 2. Summary of the 0-1 km degrees of freedom for signal (DFS) with GEO TIR and GEO TIR+VIS at 02:00, 06:00 and 12:00 UTC for all the pixels of the red square domain (land and sea pixels together) in Fig. 2, and at 06:00 and 12:00 UTC for the case of sea and land pixels. Bold values represent the highest DFS values when comparing GEO TIR and GEO TIR+VIS.

\begin{tabular}{|c|c|c|c|c|c|c|c|c|}
\hline & & \multicolumn{3}{|c|}{ All pixels } & \multicolumn{2}{|c|}{ Sea } & \multicolumn{2}{|c|}{ Land } \\
\hline & & 02:00 & 06:00 & $12: 00$ & 06:00 & $12: 00$ & 06:00 & $12: 00$ \\
\hline GEO TIR & $0-1 \mathrm{~km}$ DFS & 0.15 & 0.18 & 0.27 & 0.22 & 0.21 & 0.11 & 0.31 \\
\hline GEO TIR+VIS & $0-1 \mathrm{~km}$ DFS & 0.15 & 0.35 & 0.34 & 0.27 & 0.28 & 0.42 & 0.40 \\
\hline
\end{tabular}

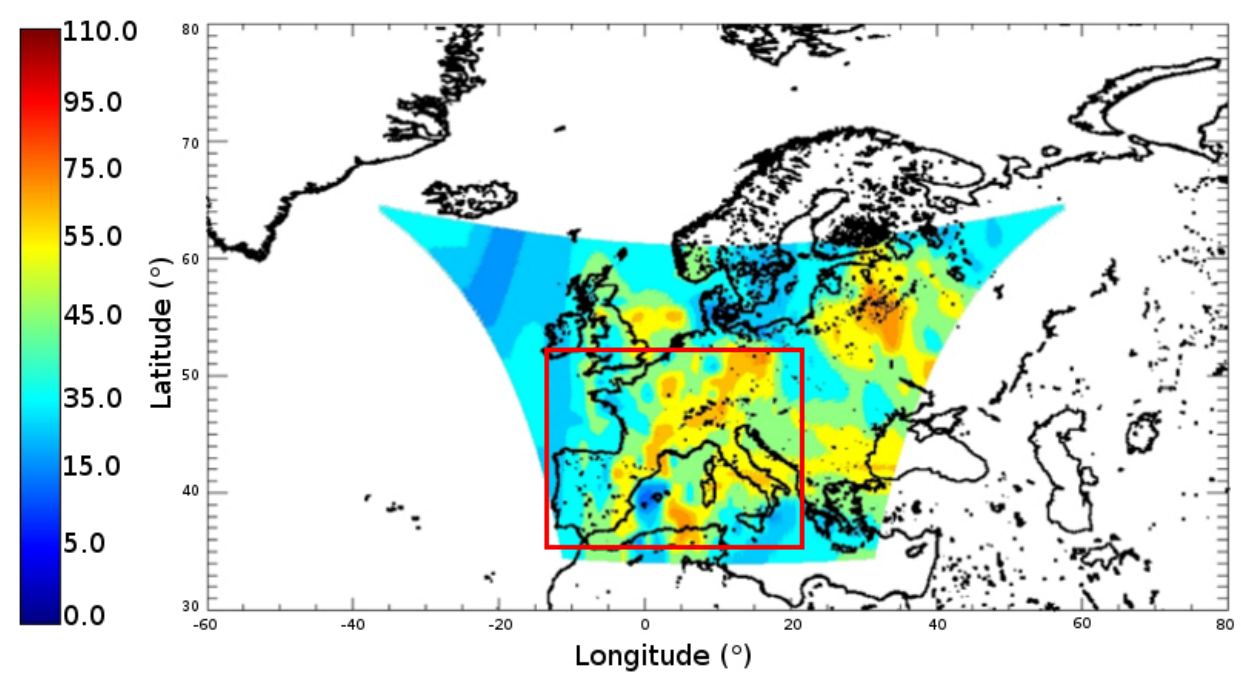

Figure 2. Image of the surface ozone field from MOCAGE 11 July 2009 at 12:00 UTC simulated with the field of view and the spatial resolution of the MAGEAQ geostationary instrument $(\sim 15 \mathrm{~km} \times 15 \mathrm{~km})$. The colour bar indicates the ozone concentration in parts per billion by volume (ppbv), with red/blue indicating relatively high/low values. The red square indicates the domain of ozone simulation with the MOCAGE grid $\left(0.5^{\circ} \times 0.5^{\circ}\right)$.

measurement. Such a GEO image contains 200000 pixels, but the smaller domain with the degraded spatial resolution has now 2000 pixels per image. This domain allows us to run simulations for extended periods of time. In this way, a full week of simulated retrievals is calculated for the two instruments GEO TIR and GEO TIR+VIS, which gives more robust statistics.

\section{Results: intercomparison between GEO TIR and GEO TIR+VIS}

This section presents an intercomparison of the data obtained from the simulator for the GEO TIR and GEO TIR+VIS instruments. We calculated retrievals for GEO TIR and GEO TIR+VIS over the domain delimited by the red square shown in Fig. 2, for the summer period between 9 and 15 July 2009. This period can be described as a typical summer, as it does not correspond to a period of extremely low or high concentrations of surface ozone. Over this period, the top of the planetary boundary layer can reach an altitude of around $400 \mathrm{~m}$ over the sea and $1 \mathrm{~km}$ above land during daytime. The efficient convective mixing in the planetary boundary layer means that we can focus on both the surface, and the $0-1 \mathrm{~km}$ column that corresponds roughly to the usual depth of the planetary boundary layer during daytime and over land. In the following sections, we will discuss the results obtained at the surface and for the $0-1 \mathrm{~km}$ column.

\subsection{Surface ozone sensitivity}

We first consider the sensitivity to surface ozone of the two different instrument concepts considered (GEO TIR and GEO TIR+VIS). This sensitivity is represented by averaging kernels $A$ (Rodgers, 2000) defined by $\mathbf{A}=\left[\mathbf{K}^{T} \mathbf{S}_{y}^{-1} \mathbf{K}+\right.$ $\left.\mathbf{S}_{\mathrm{a}}^{-1}\right]^{-1} \mathbf{K}^{T} \mathbf{S}_{y}^{-1} \mathbf{K}$. The averaging kernels can be regarded as smoothing functions of the state vector $\boldsymbol{x}$. They represent the fraction of the retrieval that comes from the data rather than the a priori, i.e. the sensitivity of the retrieval to the measurement. Averaging kernels tend to be approximately unity at levels where the retrieval is accurate. For visualization, we perform the normalization of the averaging kernels using $1 \mathrm{~km}$ layers to understand the degree of information at each vertical level. In general, the averaging kernels do not have an equidistant altitude grid. To address this, we 

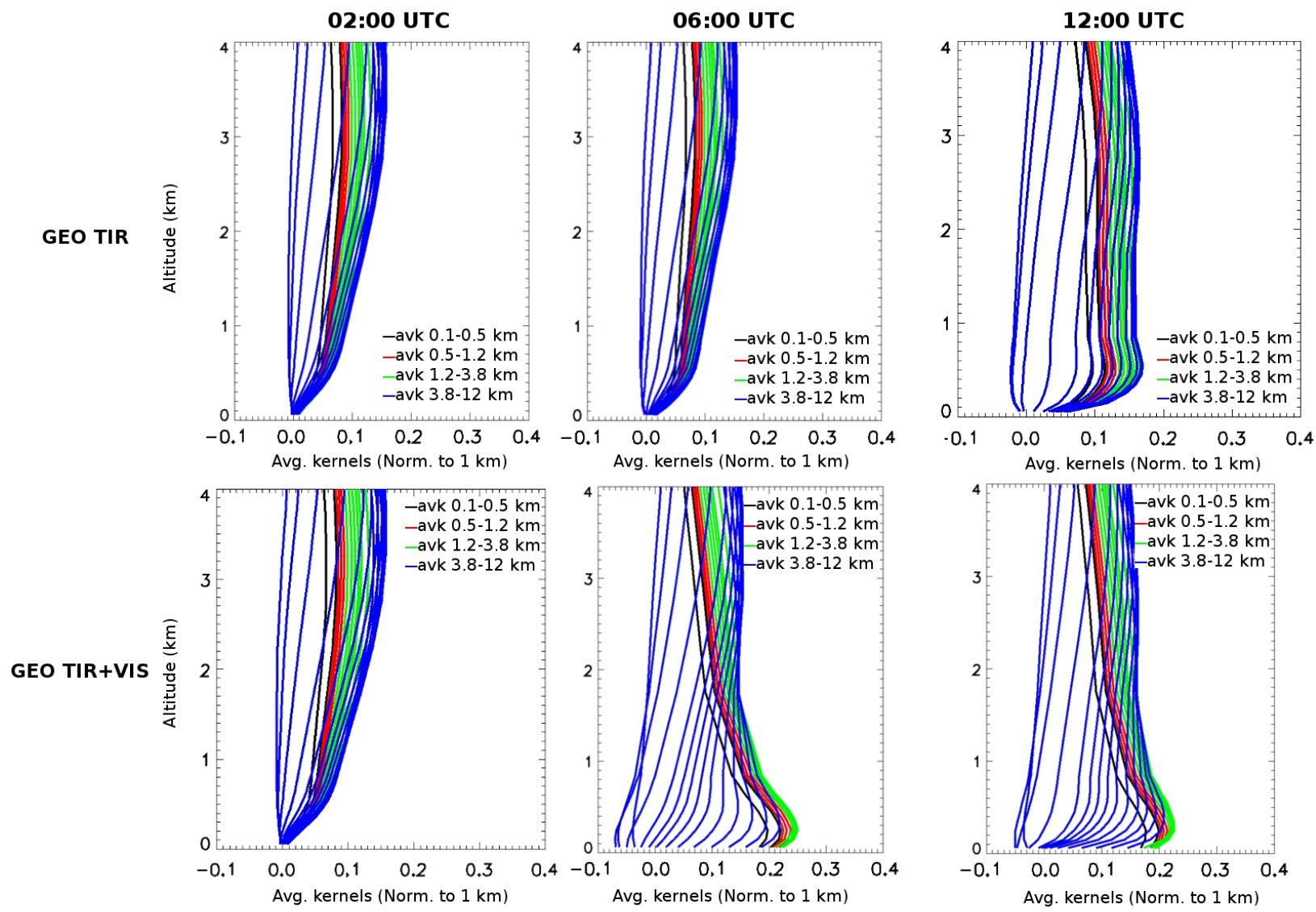

Figure 3. Mean averaging kernels (normalized to $1 \mathrm{~km}$ ), over the red square domain (over both land and sea pixels) in Fig. 2, as a function of altitude $(\mathrm{km})$ at 02:00, 06:00 and 12:00 UTC for GEO TIR (top panels) and GEO TIR+VIS (bottom panels). Black curves indicate the surface to $0.5 \mathrm{~km}$ averaging kernels, red curves indicate the 0.5 to $1.2 \mathrm{~km}$ averaging kernels, the green curves indicate the 1.2 to $3.8 \mathrm{~km}$ averaging kernels, and the blue curves indicate the 3.8 to $12 \mathrm{~km}$ averaging kernels.

normalize the averaging kernels information to $1 \mathrm{~km}$ by dividing the value of the averaging kernels by the layer thickness in the retrieval (corresponding to the layer between each chosen levels), which varies from $100 \mathrm{~m}$ (lower levels) to $8 \mathrm{~km}$ (higher levels). This approach is commonly used and more information can be found in Deeter et al. (2007) and Natraj et al. (2011). If we consider the averaging kernels averaged over the domain at different hours (Fig. 3), one can see a low sensitivity of the TIR at the surface during nighttime (02:00 UTC). The GEO TIR shows a maximum sensitivity at a height of $3 \mathrm{~km}$, which decreases and is almost zero at the surface. Since the VIS can only be used during daytime, the GEO TIR+VIS behaves similarly. During the early part of the daytime at 06:00 UTC, the GEO TIR shows the same sensitivity as at 02:00 UTC, because the thermal contrast at the surface is low, but the GEO TIR+VIS shows a maximum of sensitivity of 0.2 from the surface to about $500 \mathrm{~m}$. At 12:00 UTC, when the thermal contrast at the surface is higher, one can see that the GEO TIR has a constant sensitivity of 0.15 between $500 \mathrm{~m}$ and $4 \mathrm{~km}$. For levels below $500 \mathrm{~m}$, the sensitivity decreases quickly to less than 0.06 at the surface. The GEO TIR+VIS shows a maximum of sensitivity of 0.2 from the surface to $500 \mathrm{~m}$. Thus, the GEO TIR instrument provides a very low sensitivity near the surface and some sensitivity in the $0-1 \mathrm{~km}$ column only during favourable conditions (i.e. high thermal contrast). In contrast, the GEO TIR+VIS is able to provide extra sensitivity at the surface during daytime.

Another diagnostic that quantifies the sensitivity is the degrees of freedom for signal (DFS; Rodgers, 2000), i.e. the number of independent pieces of information that can be obtained from an observation, given by the trace of the matrix of the averaging kernels. Table 2 provides the different DFS obtained with GEO TIR and GEO TIR+VIS, for the $0-1 \mathrm{~km}$ column, at 02:00, 06:00 and 12:00 UTC, averaged over the small domain. As shown previously, the GEO TIR+VIS is more sensitive to the surface than GEO TIR - since the DFS between 0 and $1 \mathrm{~km}$ during daytime is $\sim 0.27$ for GEO TIR and $\sim 0.34$ for GEO TIR+VIS, for the average of all the pixels of the red square domain (see Fig. 2). 


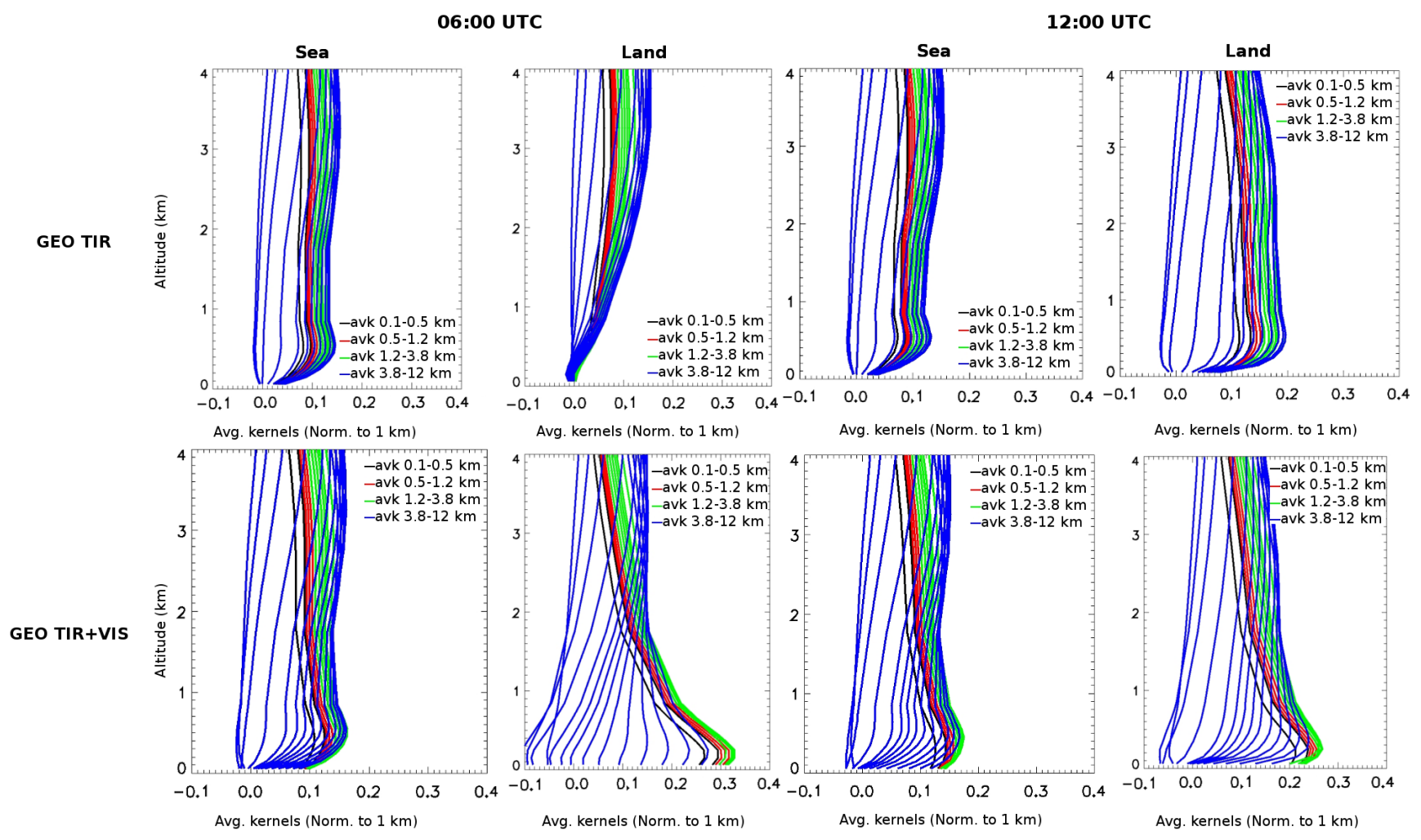

Figure 4. As in Fig. 3 except for over-sea pixels (first and third columns) and land pixels (second and fourth columns) at 06:00 UTC and 12:00 UTC.

We now compare the sensitivity of GEO TIR and GEO TIR+VIS between land and sea pixels (see Fig. 4 and Table 2). Firstly, we focus on GEO TIR results only. At 06:00 UTC over sea, GEO TIR has a low sensitivity between 0 and $1 \mathrm{~km}$. Over land, the performance is worse, as we have very low sensitivity between 0 and $1 \mathrm{~km}$ owing to the low thermal contrast. The DFS between 0 and $1 \mathrm{~km}$ is 0.22 over sea and 0.11 over land. At 12:00 UTC, over sea, GEO TIR has low sensitivity, but over land has better sensitivity owing to the increasing thermal contrast through the daytime. This is reflected in the DFS between 0 and $1 \mathrm{~km}$, which is 0.21 over sea and 0.31 over land. We now discuss the GEO TIR+VIS results. At 06:00 UTC over land, we have a better sensitivity to the surface than over sea, with the $0-$ $1 \mathrm{~km}$ DFS over sea being 0.27 and over land 0.42 . The sensitivity of GEO TIR+VIS at 12:00 UTC is very similar. The sensitivity is better over land than over sea, with the $0-1 \mathrm{~km}$ DFS being 0.28 over sea and 0.40 over land.

For the GEO TIR+VIS, the simultaneous simulated retrievals of $\mathrm{H}_{2} \mathrm{O}$, temperature profiles and surface albedo, together with the retrievals of $\mathrm{O}_{3}$ profiles provide a significant amount of information on $\mathrm{O}_{3}$ values in the $0-1 \mathrm{~km}$ column. In particular, they provide better information during the daytime than those given by the GEO TIR. The GEO TIR+VIS instrument improves the sensitivity in the $0-1 \mathrm{~km}$ column during daytime compared to GEO TIR. These improvements are more pronounced for land pixels that are the main target for AQ monitoring purposes.

Another way to analyse these results is to study the values of the DFS representative of the $0-1 \mathrm{~km}$ column over Europe for GEO TIR and GEO TIR+VIS only during daytime (Fig. 5). In Fig. 5, the impact of the VIS band is obvious with higher DFS values on the domain showing a higher sensitivity at the lowermost layers. In addition, the highest sensitivities are over land where precise ozone measurements are crucial for AQ monitoring. Figure 6 presents the altitude of the maximum of the surface averaging kernels for GEO TIR and GEO TIR+VIS during daytime, which corresponds to the maximum sensitivity. For GEO TIR, the maximum sensitivity is located at about $3 \mathrm{~km}$, but depends on the surface type: over land, the maximum is close to $2 \mathrm{~km}$ and over sea it is close to $4 \mathrm{~km}$. However, for GEO TIR+VIS, the maximum sensitivity is at much lower altitude, namely about $300 \mathrm{~m}$ depending also on the surface type with lower altitude values over land and higher values over sea.

\subsection{Ozone retrievals over a week period}

We consider the intercomparison between GEO TIR and GEO TIR+VIS simulated observations and the performance over a 1 week period in this section. A statistical analysis is done by using the $z$ test, the correlation coefficient between 
0-1 km DFS average over 9-15 July 2009 period during daytime (07:00 - 17:00 UTC)

GEO TIR

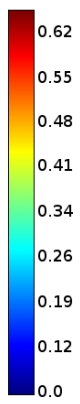

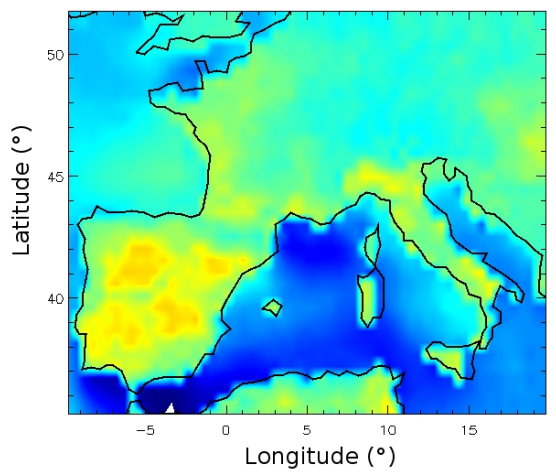

GEO TIR+VIS

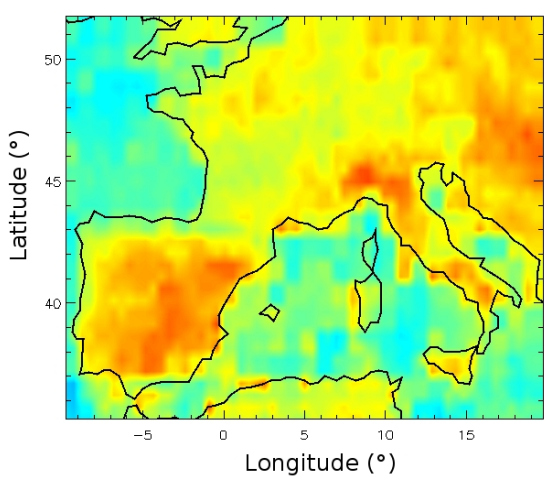

Figure 5. DFS values for GEO TIR (left panel) and GEO TIR+VIS (right panel) over Europe and averaged over the daytime (07:0017:00 UTC) period from 9 to 15 July 2009. The colour bar indicates the different DFS values, with red/blue indicating relatively high/low values.

Max. height of the surf. AVK over 9-15 July 2009 period during daytime (07:00 - 17:00 UTC)

GEO TIR
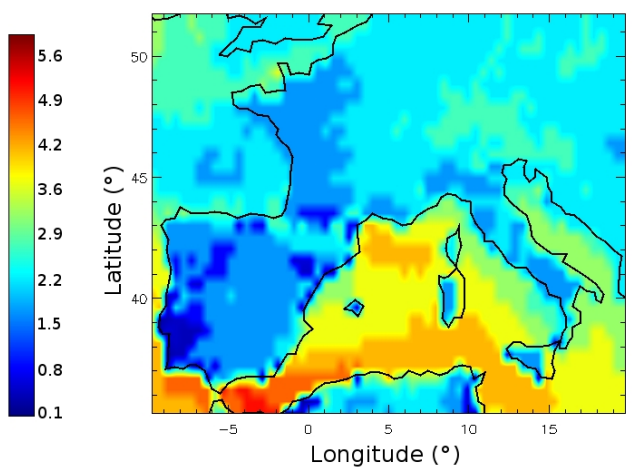

GEO TIR + VIS

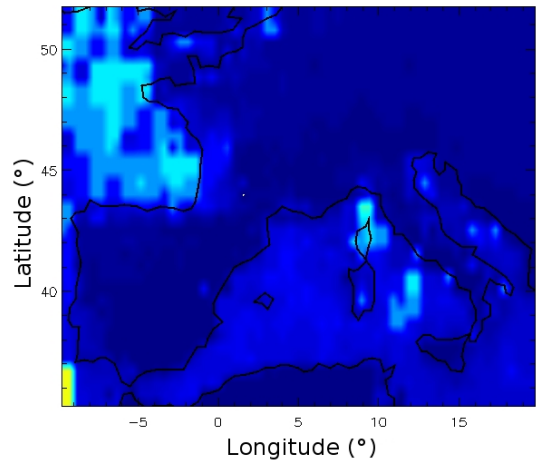

Figure 6. As in Fig. 5 but for the height $(\mathrm{km})$ of the surface averaging kernels maximum. The colour bar indicates the different height value in $\mathrm{km}$, with red/blue indicating relatively high/low levels.

the simulated observations and the reference state, and the standard deviation of the simulated observations compared to the reference state. The $z$ test has been used in OSSEs before to test the significance of differences between data sets (see Claeyman et al., 2011a; Lahoz et al., 2005). In order to highlight the differences between the results of the statistical tests comparing GEO TIR and GEO TIR+VIS, we calculate the $z$ test for the $0-1 \mathrm{~km}$ ozone column only during daytime (07:00-17:00 UTC) (figure not shown). The result of the $z$ test shows that over most of the domain of interest, the GEO TIR and GEO TIR+VIS configurations are significantly different at the $99 \%$ significance level. This confirms that the two data sets corresponding to GEO TIR and GEO TIR+VIS contain significantly different information.

Figure 7 presents the $0-1 \mathrm{~km}$ ozone column of the reference state, the GEO TIR, and the GEO TIR+VIS configurations, for 11 July 2009 at 16:00 UTC, as an example. For GEO TIR, the ozone values are globally underestimated but distinctive local features with high ozone values are well represented (e.g. over Spain and Italy). Conversely, for GEO TIR+VIS, the ozone distribution is closer to the reference state: the bias is reduced and the representation of the ozone field is better.

Figure 8 shows the values of the correlation coefficient and the standard deviation over time. This information is compared to the reference state for the surface and for the $0-1 \mathrm{~km}$ column, for GEO TIR and GEO TIR+VIS. The ozone correlations for GEO TIR and GEO TIR+VIS show a diurnal variability that corresponds to the thermal contrast variation, also in agreement with the diurnal cycle of ozone (maximum during daytime and minimum during night-time). An additional diurnal variability corresponding to the amount of sunlight is seen for the GEO TIR+VIS compared to the GEO TIR. As expected, during night-time, the simulated ozone correlations between GEO TIR and GEO TIR+VIS compared to the reference state are the same. During daytime, for the $0-1 \mathrm{~km}$ ozone column, there is an increase of 0.1 for the correlation coefficient from 0.65 (GEO TIR) to 0.75 (GEO TIR+VIS). 

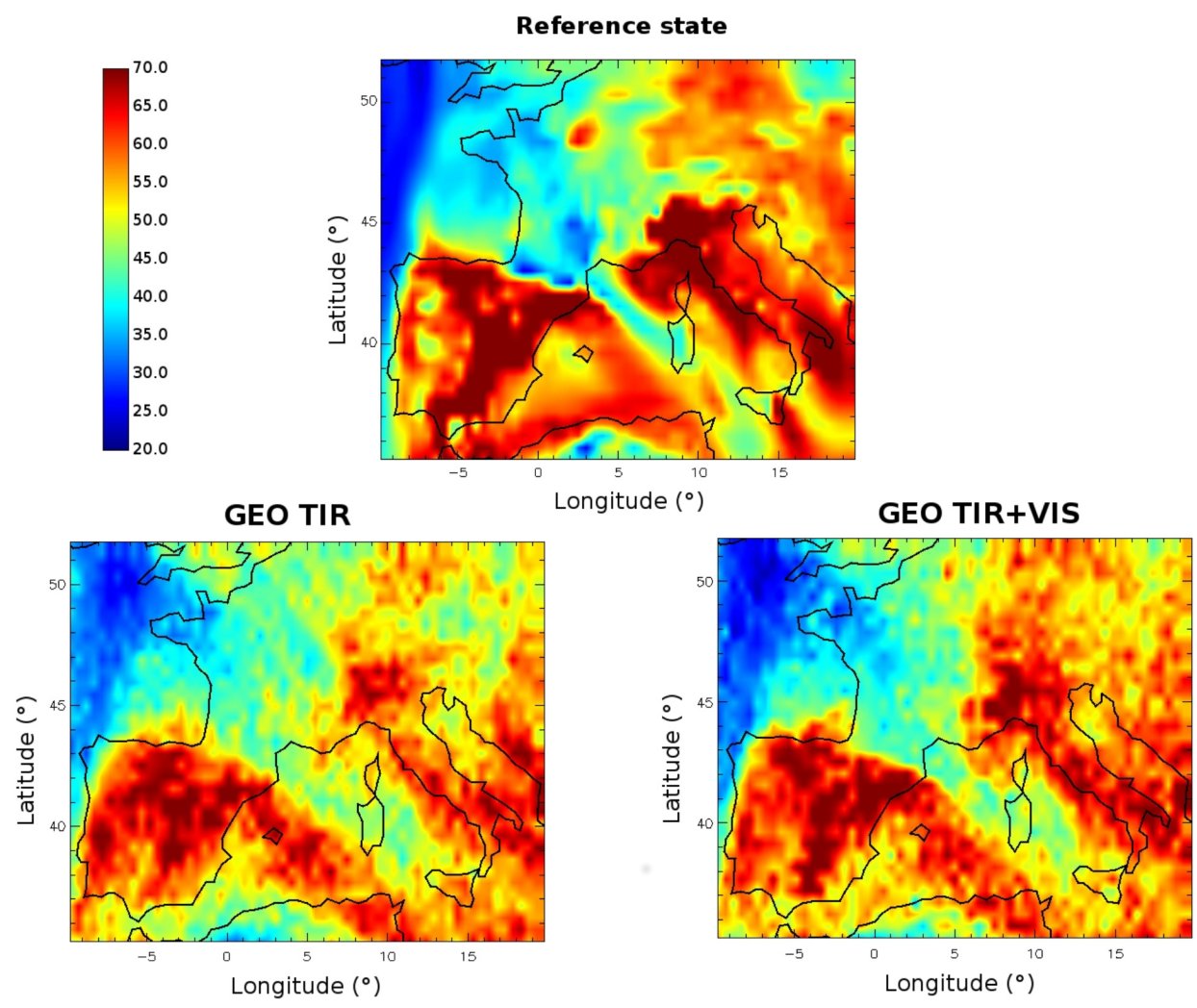

Figure 7. 0-1 km ozone column (ppbv) for the 11 July 2009 at 16:00 UTC for the reference state (top), GEO TIR (bottom left panel) and GEO TIR+VIS (bottom right panel). The colour bar indicates the ozone concentration in parts per billion by volume (ppbv), with red/blue indicating relatively high/low values.

The correlation at the surface also shows a diurnal variability, but the peaks of the maximum correlation are narrower; during daytime, GEO TIR+VIS gives an average correlation peaking at 0.6 while GEO TIR peaks at 0.5 . The a priori is not correlated with the reference state with a correlation less than 0.2 . Thus, the simulated observations are more highly correlated with the reference state than the a priori. The complementarity between TIR and VIS observations improves considerably the correlation between GEO TIR+VIS observations and the reference state, compared with the correlation between GEO TIR observations and the reference state.

The standard deviation shows the same behaviour as the correlation coefficients. During daytime, GEO TIR and GEO TIR+VIS have lower standard deviations compared to the reference state than between the a priori and the reference state. During daytime, the $0-1 \mathrm{~km}$ standard deviation of GEO TIR+VIS is lower than the $0-1 \mathrm{~km}$ standard deviation of GEO TIR by $15 \%$. The same behaviour is seen for the daytime surface standard deviation (Fig. 8).

Finally, Fig. 9 shows the $0-1 \mathrm{~km}$ DFS that reflects the variation of the sensitivity of GEO TIR and GEO TIR+VIS over time. As expected, during night-time, GEO TIR and GEO TIR+VIS have the same sensitivity. During daytime, the sensitivity of GEO TIR is closely linked to the thermal contrast, so the sensitivity increases in the morning, reaches a maximum at the beginning of the afternoon, and decreases toward the end of the day. The $0-1 \mathrm{~km}$ DFS peak has an average value of 0.26. Conversely, the sensitivity of GEO TIR+VIS is linked to both the amount of sunlight (VIS part of the instrument) and to the thermal contrast (TIR part of the instrument). Thus, the $0-1 \mathrm{~km}$ DFS shows a considerable increase in the early morning, stabilizes during mid-morning, increases at the end of the morning and beginning of afternoon, reaches a maximum during the afternoon, and decreases at the end of the day. The $0-1 \mathrm{~km}$ DFS peak has an average value of 0.36 .

Now, we compare land and sea pixels to show the variation over time of the statistical parameters (correlation, standard deviation, and 0-1 km DFS). Focusing first on the sea pixels, Fig. 10 shows that the correlation has a diurnal cycle which is less pronounced than the correlation in the sea+land results for GEO TIR and GEO TIR+VIS. During daytime, an increase of 0.1 on the $0-1 \mathrm{~km}$ ozone column correlation for GEO TIR+VIS is calculated compared to the $0-1 \mathrm{~km}$ ozone column correlation for GEO TIR. However, there is no clear difference between the GEO TIR and GEO TIR+VIS surface ozone correlations. The same behaviour is observed for the standard deviation. The $0-1 \mathrm{~km}$ ozone column standard 


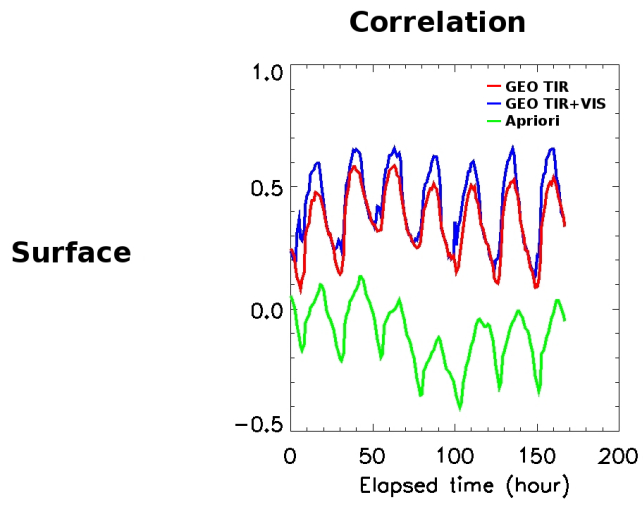

\section{Standard deviation (ppbv)}
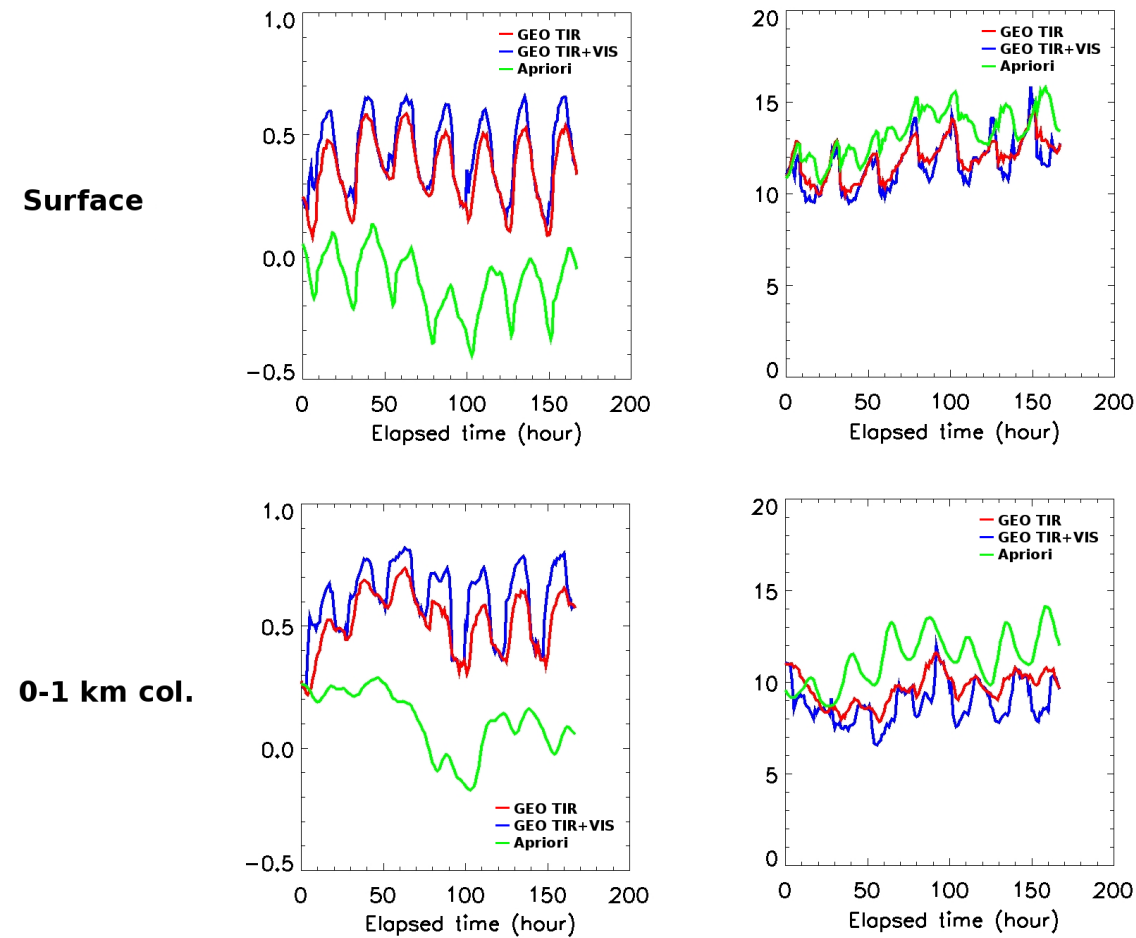

Figure 8. Time series of ozone correlation (left column, dimensionless) and standard deviation (right column, ppbv) between GEO TIR (red lines), GEO TIR+VIS (blue lines) and the reference state. This is calculated for all pixels of the red square domain (see Fig. 2) for the period between 9 to 15 July 2009. The green line shows the results obtained with the a priori. The first row corresponds to the surface ozone results and the second row corresponds to the $0-1 \mathrm{~km}$ ozone column results.

DFS 0-1 km col.

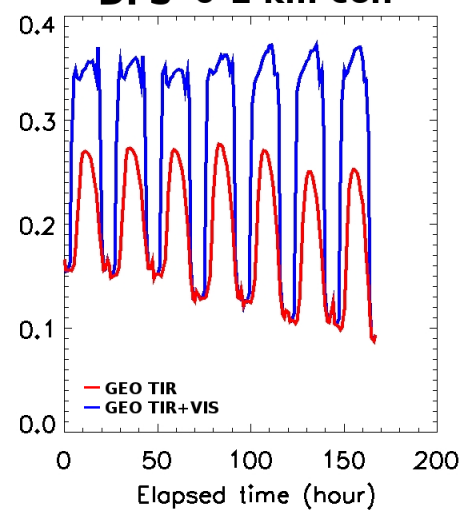

Figure 9. $0-1 \mathrm{~km}$ DFS, for all the pixels of the red square domain (see Fig. 2), over time (period between the 9 to 15 July 2009) for GEO TIR (in red) and GEO TIR+VIS (in blue).

deviation of GEO TIR+VIS is lower than that of GEO TIR, but no difference is calculated for the surface ozone standard deviation. Figure 11 shows that the GEO TIR average maximum is 0.18 for the $0-1 \mathrm{~km}$ DFS. For GEO TIR+VIS, the $0-1 \mathrm{~km}$ DFS shows an average maximum of 0.3. Compared to the previous set of results of GEO TIR and GEO TIR+VIS that considered all the pixels of the domain delimited by the red square (see Fig. 2), GEO TIR and GEO TIR+VIS are less efficient at retrieving sea pixels, particularly at the surface. This can be explained by the lower thermal contrast over the sea, and since the sea acts as a temperature reservoir, there is less variability associated with the diurnal cycle. Also, for the VIS, the albedo of the sea is small, and therefore the sensitivity at the surface added by the VIS over sea is relatively low.

For the land pixels, Fig. 10 shows the signature of the diurnal cycle. For GEO TIR, the $0-1 \mathrm{~km}$ ozone column correlation average maximum is about 0.6 and the surface ozone correlation average maximum is 0.55 . For GEO TIR+VIS, the $0-1 \mathrm{~km}$ ozone column correlation average maximum is around 0.75 and the surface ozone correlation average maximum is around 0.65 . For the standard deviation, during daytime, GEO TIR+VIS provides a significant improvement. On average this is a reduction of $20 \%$ for the $0-1 \mathrm{~km}$ ozone column and a reduction of $10 \%$ for the surface ozone, compared to the GEO TIR standard deviation. Finally, in Fig. 11, the GEO TIR 0-1 km DFS shows high variability during the diurnal cycle, the $0-1 \mathrm{~km}$ DFS average peak being 0.32 . For the GEO TIR+VIS, the $0-1 \mathrm{~km}$ DFS average peak is 0.4. 
Sea
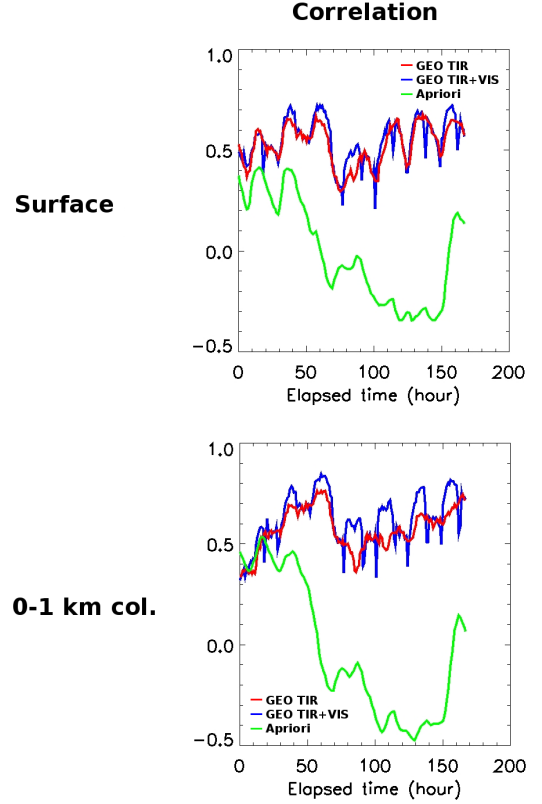
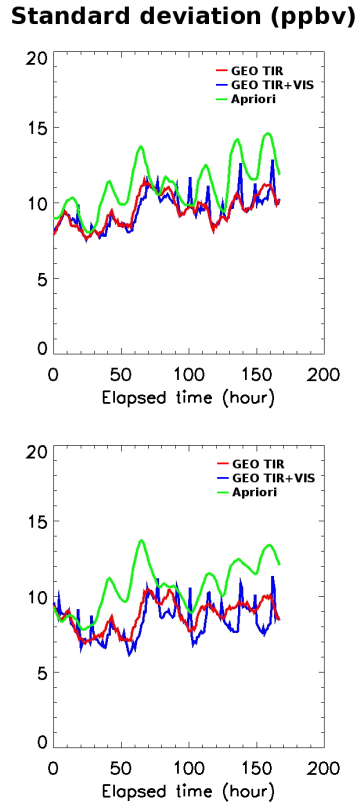

Land
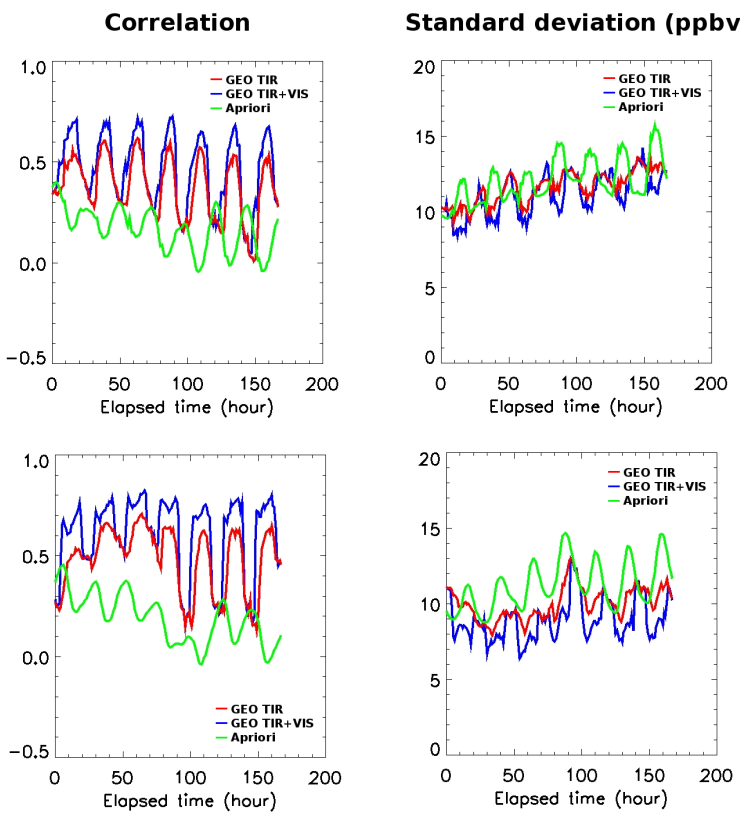

Figure 10. As in Fig. 8 but for the sea pixels (first and second column) and land pixels (third and fourth column). First and third columns show the correlation; second and fourth columns show the standard deviation.

Sea

DFS 0-1 km col.

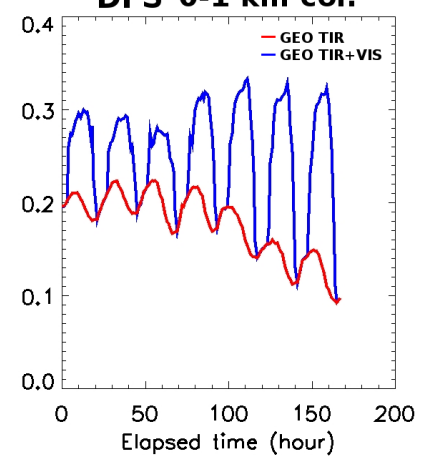

Land

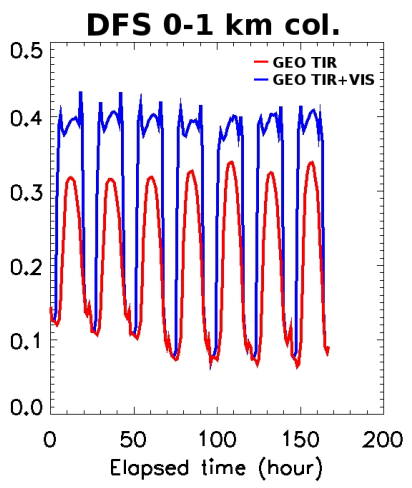

Figure 11. As in Fig. 9 but for the sea pixels (first column) and land pixels (second column).

As for the case of the results for GEO TIR and GEO TIR+VIS considering all the pixels of the domain delimited by the red square (see Fig. 2), the GEO TIR+VIS is considerably more efficient than the GEO TIR in terms of sensitivity, correlation and standard deviation, for both the $0-1 \mathrm{~km}$ column results and the surface results.

\subsection{Air quality monitoring}

The final intercomparison between the GEO TIR and GEO TIR+VIS instruments addresses their efficiency at monitoring AQ. The current European legislation for health

protection is used, in particular the European directive (2008/50/CE), which sets a threshold for the determination of a bad AQ event arising from high ozone concentrations. The threshold considered for the surface ozone concentration is nowadays $120 \mu \mathrm{g} \mathrm{m}^{-3}$ for an $8 \mathrm{~h}$ consecutive period. This threshold is calculated using the daily maximum of an $8 \mathrm{~h}$ running average of the ozone surface value. The accuracy (ACC), the probability of detection (PD) and the false alarm rate (FAR) for the GEO TIR and GEO TIR+VIS instruments are calculated as follows:

$$
\begin{aligned}
\mathrm{ACC} & =100 \times \frac{\left(R_{1} \_S_{1}+R_{0 \_} S_{0}\right)}{N} \\
\mathrm{PD} & =100 \times \frac{R_{1 \_} S_{1}}{R_{1}} \\
\mathrm{FAR} & =100 \times \frac{R_{0 \_} S_{1}}{R_{0}},
\end{aligned}
$$

where $R_{1} S_{1}$ represents the number of surface grid points where both the reference state and the simulated observations are higher than the threshold, and $R_{0} S_{0}$ represents the number of surface grid points where both the reference state and the simulated observations are lower than the threshold. $N$ is the total number of surface grid points (number of pixels of the red square domain, see Fig. 2). $R_{1}$ represents the number of surface grid points where the reference state is higher than the threshold. $R_{0} S_{1}$ represents the number of surface grid points where the reference state is lower than the threshold and the simulated observations are higher than the threshold. 
Table 3. Air quality monitoring results for GEO TIR and GEO TIR+VIS. For all the pixels of the red square domain (land and sea pixels together) in Fig. 2, the land pixels, and the sea pixels, we calculate the accuracy (ACC), the probability detection (PD) and the false alarm rate (FAR). See Sect. 3.2 for more details. Bold values represent the best values in the comparison between GEO TIR and GEO TIR+VIS.

\begin{tabular}{lccccccc}
\hline & \multicolumn{3}{c}{ GEO TIR } & & \multicolumn{3}{c}{ GEO TIR+VIS } \\
\cline { 2 - 4 } \cline { 7 - 8 } & ACC & PD & FAR & & ACC & PD & FAR \\
\hline Global data & 70.78 & 28.72 & $\mathbf{1 0 . 8 1}$ & & $\mathbf{7 5 . 3 7}$ & $\mathbf{4 9 . 4 5}$ & 13.29 \\
Sea pixels & 65.62 & 10.40 & $\mathbf{1 . 5 5}$ & & $\mathbf{7 0 . 6 9}$ & $\mathbf{2 6 . 5 6}$ & 3.08 \\
Land pixels & 74.48 & 47.86 & $\mathbf{1 6 . 3 9}$ & & $\mathbf{7 8 . 7 2}$ & $\mathbf{7 3 . 3 6}$ & 19.44 \\
\hline
\end{tabular}

$R_{0}$ represents the number of surface grid points where the reference state is lower than the threshold.

Table 3 presents the ACC, PD, FAR percentages for the GEO TIR and GEO TIR+VIS configurations for the case where sea and land pixels are included together, where only sea pixels are included, and when only land pixels are included. For all pixels, GEO TIR has an ACC close to $70 \%$ (65\% and $74 \%$ for sea and land pixels, respectively), but a PD of around $30 \%$ (10\% and $48 \%$ for sea and land pixels, respectively) and a FAR around $11 \%(1 \%$ and $16 \%$ for sea and land pixels, respectively). Thus, GEO TIR has a higher likelihood of missing a real ozone peak than to detect it, and when the instrument detects an ozone peak, GEO TIR has a likelihood of one in ten that it is a false alarm for the domain. For pixels over land, the domain of interest for monitoring AQ, we have a likelihood of one in six that it is a false alarm.

The results for all pixels for GEO TIR+VIS show that we have an ACC close to $75 \%$ (70\% and $79 \%$ for sea and land pixels, respectively). We have a PD close to $50 \%$ ( $26 \%$ and $73 \%$ for sea and land pixels, respectively), and we have a FAR close to $13 \%$ (3\% and $20 \%$ for sea and land pixels, respectively). Therefore, one can see that GEO TIR+VIS always performs better than GEO TIR in terms of ACC and $P D$, and with just a slightly higher rate of false alarms. Note that for the GEO TIR+VIS over land, the domain of interest for monitoring $\mathrm{AQ}$, we have a PD that reaches the value of $73 \%$; this is more than $25 \%$ better than the PD obtained with GEO TIR over land.

To get a better idea of the detection behaviour of the GEO TIR and GEO TIR+VIS instruments, we consider the receiver operating characteristic (ROC) curves (Fig. 12) by calculating the changes in PD and FAR when we modify the threshold, and then we plot the PD against the FAR. Figure 12 shows the ROC plot calculated for the daily maximum of the $8 \mathrm{~h}$ running average of the surface values over land pixels.

For a weaker threshold value (less than $100 \mu \mathrm{g} \mathrm{m}^{-3}$ ), GEO TIR and GEO TIR+VIS are quite similar in terms of PD and FAR, likely because this threshold value is too close

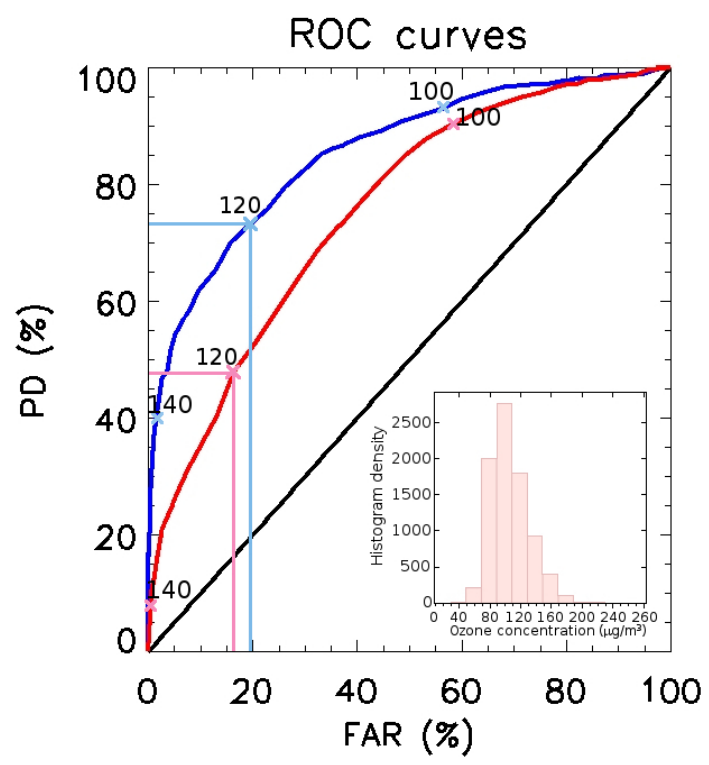

Figure 12. Receiver operating characteristic (ROC) curves, that represent the probability of detection (PD) vs. the false alarm rate (FAR) considering the pixels for daytime (07:00-17:00 UTC) over land at the surface. In black is plotted the equal likelihood line, in blue the ROC curve for GEO TIR+VIS and in red the ROC curve for GEO TIR. The ROC curves are calculated for air quality purposes, and we highlight the value corresponding to the European threshold (2008/50/CE) for health protection of a surface ozone concentration of $120 \mathrm{\mu g} \mathrm{m}^{-3}$, measured for the daily maximum of the $8 \mathrm{~h}$ running average of the surface values. As a complementary information, two other thresholds (100 and $\left.140 \mu \mathrm{g} \mathrm{m}^{-3}\right)$ are highlighted. Also the histogram of the distribution of the daily ozone maximum of the $8 \mathrm{~h}$ running average of the surface values of the reference state is shown.

to the a priori to represent the sensitivity added by the two instruments. Conversely, for higher threshold values, GEO TIR+VIS improves the PD compared to GEO TIR for a quite similar FAR. In the same way, this shows a FAR of about $20 \%$, corresponding to the threshold of $120 \mu \mathrm{g} \mathrm{m}^{-3}$, with a probability of detection of about $75 \%$ and less than $50 \%$ for GEO TIR+VIS and GEO TIR, respectively. For threshold values greater than $140 \mathrm{\mu g} \mathrm{m}^{-3}$, the number of pixels is too low to obtain meaningful PD and FAR statistics. In Fig. 12, we also represent the histogram of the ozone concentration from the reference state that shows the bounds for which the calculations of PD and FAR are valid. These ROC curves are dependent on the distribution of the ozone fields of the reference state. Therefore, GEO TIR+VIS clearly shows a better detection performance than GEO TIR concerning the European directive (2008/50/CE) threshold for health protection.

\section{Conclusions}

In this paper, we compare two geostationary satellite (GEO) instrument configurations for sampling ozone in the 
lowermost troposphere (surface and the $0-1 \mathrm{~km}$ height region). Ozone is an AQ hazard in the lowermost troposphere. These configurations represent two grating spectrometers operating in the TIR (GEO TIR), and in the TIR with a VIS channel (GEO TIR+VIS). The added value of the GEO TIR+VIS configuration compared to the GEO TIR configuration is quantified by comparing: (i) their sensitivity to surface ozone; (ii) the performance of ozone profile retrievals from these configurations, and that of a priori ozone profile information, against an ozone reference state simulated with the chemical transport model MOCAGE; and (iii) AQ threshold analysis. This comparison considers land and sea pixels for surface ozone and $0-1 \mathrm{~km}$ ozone column. The metrics used to quantify the relative performance of the configurations include the averaging kernels and the degrees of freedom for signal (DFS), and the statistical metrics used to quantify the performance of the configurations against the reference state include $z$ test, correlation, standard deviation, DFS, height of maximum of surface averaging kernels and receiver operating characteristic (ROC) curves.

We find that the GEO TIR+VIS configuration provides more information on both surface ozone and the $0-1 \mathrm{~km}$ ozone column than the GEO TIR configuration during daytime (during night-time, the VIS channel is not operational). The metrics considered also show that the GEO TIR+VIS configuration is closer to the reference state than both the GEO TIR configuration and ozone a priori information. Statistical tests indicate that the GEO TIR+VIS configuration is significantly closer to the reference state than the GEO TIR configuration. Correlation and standard deviation indicate that the addition of the VIS channel to the TIR instrument improves the simulated ozone observations compared to the reference state. DFS and the maximum of the surface averaging kernels show an enhancement in sensitivity in the lowermost layers including the boundary layer during daytime for the GEO TIR+VIS configuration vs. the GEO TIR configuration. Finally, the ROC curves clearly show the added value of the GEO TIR+VIS vs. the GEO TIR by calculating for a similar false alarm rate of $\sim 20 \%$ an improved probability of detection of $\sim 75 \%$ for GEO TIR+VIS compared to less than $50 \%$ for GEO TIR. These values correspond to the threshold of $120 \mu \mathrm{g} \mathrm{m}^{-3}$ used nowadays in the European directive 2008/50/CE for health protection.

However, these results need to be taken with caution as several assumptions have been made. As discussed in this paper, we do not take into account clouds and aerosols. The assumption on the clouds is likely to be applicable as the goal of the instrument is to monitor air quality, in particular to monitor high ozone episodes, commonly associated with an anticyclonic situation (i.e. a cloud-free situation). In addition, this study is a comparison between two instrument configurations, and thus provides relative results. The assumption on aerosols is more problematic as aerosols impact the radiances in the visible and degrade the quality of the retrieval, in particular in the Chappuis band, but because of the difficulty of accurately modelling and measuring their properties (Timmermans et al., 2009), we have chosen not to take the aerosols into account in this first approximation to the problem. Moreover, this study only considers a Lambertian surface with a spectral albedo interpolated using a third-order polynomial. This representation of the surface properties neglects the uncertainties that are likely in reality due to the bidirectional reflectance distribution function (BRDF) and to the spectral signatures of surface and vegetation properties (Richter et al., 2012). Future improvements of this study will concern better modelling and retrieval of aerosols and surface properties. Finally, we also neglect the mismatches between the cross sections used in the radiative transfer model and the real cross sections. Considering that measurements of cross sections are made in the laboratory with errors which contribute to the retrieval error, these uncertainties could be significant (Liu et al., 2007; Gorshelev et al., 2014). The quality of the retrievals relies also on improvements in the laboratory measurements and in the modelling of these cross sections.

Bearing in mind the assumptions made, these results suggest that a GEO TIR+VIS configuration provides significantly more information on surface ozone and the $0-1 \mathrm{~km}$ ozone column than a GEO TIR configuration. The TIR+VIS configuration would thus be worth considering as an addition to the Global Observing System for monitoring AQ. Future work will take into account the influence of the aerosols and the polarization on the retrieval and provide more realistic results, e.g. including the impact of the scrambler geometry on the instruments, and the slit's pseudo-noise. Moreover, future work will include performing an OSSE using assimilation products instead of using only retrievals to test further the results in this work and assess the impact that observation errors have on the comparison between the GEO TIR+VIS and GEO TIR configurations.

Acknowledgements. This work was funded by the Centre National de Recherches Scientifiques (CNRS) and the Centre National de Recherches Météorologiques (CNRM) of Météo-France. JLA and WL were supported by the RTRA/STAE foundation. EH and JLA thank also the Région Midi Pyrénées (INFOAIR project) and ASTRIUM-EADS for their strong support. This work was performed using HPC resources from GENCI-TGCC (grant 2012-t2012016951) and GENCI-IDRIS (grant 2013-t2013016951). We acknowledge the referee and the editor for their corrections and their reports that helped to improve the quality of the paper.

Edited by: M. Hamilton 


\section{References}

Bechtold, P., Bazile, E., Guichard, F., Mascart, P., and Richard, E.: A mass-flux convection scheme for regional and global models, Q. J. Roy. Meteor. Soc., 127, 869-886, 2001.

Bousserez, N., Attie, J. L., Peuch, V. H., Michou, M., Pfister, G., Edwards, D., Emmons, L., Mari, C., Barret, B., Arnold, S. R., Heckel, A., Richter, A., Schlager, H., Lewis, A., Avery, M., Sachse, G., Browell, E. V., and Hair, J. W.: Evaluation of the MOCAGE chemistry transport model during the ICARTT/ITOP experiment, J. Geophys. Res.-Atmos., 112, D10S42, doi:10.1029/2006JD007595, 2007.

Brasseur, G. P., Prinn, R. G., and Alexander, A. P.: Atmospheric Chemistry in a Changing World,ISSN 1619-2435, ISBN 3-54043050-4, Springer-Verlag Berlin Heidelberg New York, 300 pp., 2003.

Brion, J., Chakir, A., Daumont, D., Malicet, J., and Parisse, C.: High-resolution laboratory absorption cross section of $\mathrm{O}_{3}$ : temperature effect, Chem. Phys. Lett., 213, 610-612, 1993.

Brion, J., Chakir, A., Charbonnier, J., Daumont, D., Parisse, C., and Malicet, J.: Absorption spectra measurements for the ozone molecule in the 350-830 nm region, J. Atmos. Chem., 30, 291299, 1998

Brunekreef, B. and Holgate, S.: Air pollution and health, Lancet, 360, 1233-1242, 2002.

Burrows, J. P., Bergametti, G., Bovensmann, H., Flaud, J.-M., Orphal, J., Noël, S., Monks, P., Corlett, G., Goede, A. P., von Clarmann, T., Steck, T., Fischer, H., and Friedl-Vallon, F.: The Geostationary Tropospheric Pollution Explorer (GeoTROPE) mission: objectives and requirements, Adv. Space Res., 34, 682-687, 2004.

Carli, B., Aubertin, G., Birk, M., Carlotti, M., Castelli, E., Ceccherini, S., D’ Alba, L., Dehn, A., De laurentis, M., Dinelli, B. M., Dudhia, A., Fehr, T., Fischer, H., Flaud, J. M., Funke, B., Gessner, R., Höpfner, M., Kiefer, M., Lopez-Puertas, M., Oelhaf, H., Perron, G., Kleinert, A., Mosner, P., Niro, F., Raspollini, P., Remedios, J., Ridolfi, M., Sembhi, H., Sgheri, L., von Clarmann, T., Wagner, G., and Weber, H.: The Global Picture of the Atmospheric Composition Provided by MIPAS on ENVISAT, in: IEEE International Symposium on Geoscience and Remote Sensing IGARSS, 1860-1863, 2012.

CEOS: A Geostationary Satellite Constellation for Observing Global Air Quality: An International Path Forward, CEOS Atmospheric Composition Constellation, version 4, 41 pp., available at: available at: www.ceos.org/images/ACC/AC_Geo_Position_ Paper_v4.pdf (last access: July 2014), 2011.

Chance, K., Liu, X., Suleiman, R. M., Flittner, D. E., Al-Saadi, J., and Janz, S. J.: Tropospheric Emissions: Monitoring of Pollution (TEMPO), Earth Observing Systems XVIII, Proc. SPIE 8866, 88660D, 2013.

Claeyman, M., Attié, J.-L., Peuch, V.-H., El Amraoui, L., Lahoz, W. A., Josse, B., Joly, M., Barré, J., Ricaud, P., Massart, S., Piacentini, A., von Clarmann, T., Höpfner, M., Orphal, J., Flaud, J.M., and Edwards, D. P.: A thermal infrared instrument onboard a geostationary platform for $\mathrm{CO}$ and $\mathrm{O}_{3}$ measurements in the lowermost troposphere: Observing System Simulation Experiments (OSSE), Atmos. Meas. Tech., 4, 1637-1661, doi:10.5194/amt-41637-2011, 2011a.

Claeyman, M., Attié, J.-L., Peuch, V.-H., El Amraoui, L., Lahoz, W. A., Josse, B., Ricaud, P., von Clarmann, T., Höpfner, M., Or- phal, J., Flaud, J.-M., Edwards, D. P., Chance, K., Liu, X., Pasternak, F., and Cantié, R.: A geostationary thermal infrared sensor to monitor the lowermost troposphere: $\mathrm{O}_{3}$ and $\mathrm{CO}$ retrieval studies, Atmos. Meas. Tech., 4, 297-317, doi:10.5194/amt-4-297-2011, 2011b.

Clerbaux, C., Boynard, A., Clarisse, L., George, M., Hadji-Lazaro, J., Herbin, H., Hurtmans, D., Pommier, M., Razavi, A., Turquety, S., Wespes, C., and Coheur, P.-F.: Monitoring of atmospheric composition using the thermal infrared IASI/MetOp sounder, Atmos. Chem. Phys., 9, 6041-6054, doi:10.5194/acp-9-6041-2009, 2009.

Cuesta, J., Eremenko, M., Liu, X., Dufour, G., Cai, Z., Höpfner, M., von Clarmann, T., Sellitto, P., Foret, G., Gaubert, B., Beekmann, M., Orphal, J., Chance, K., Spurr, R., and Flaud, J.-M.: Satellite observation of lowermost tropospheric ozone by multispectral synergism of IASI thermal infrared and GOME-2 ultraviolet measurements over Europe, Atmos. Chem. Phys., 13, 9675-9693, doi:10.5194/acp-13-9675-2013, 2013.

Daumont, M., Brion, J., Charbonnier, J., and Malicet, J.: Ozone UV spectroscopy, I: absorption cross-sections at room temperature, J. Atmos. Chem., 15, 145-155, 1992.

Deeter, M., Edwards, D., Gille, J., and Drummond, J.: Sensitivity of MOPITT observations to carbon monoxide in the lower troposphere, J. Geophys. Res., 112, D24306, doi:10.1029/2007JD008929, 2007.

Dominici, F., Peng, R. D., Barr, C. D., and Bell, M. L.: Protecting human health from air pollution shifting from a single-pollutant to a multipollutant approach, Epidemiology, 21, 187-194, 2010.

Fischer, H., Birk, M., Blom, C., Carli, B., Carlotti, M., von Clarmann, T., Delbouille, L., Dudhia, A., Ehhalt, D., Endemann, M., Flaud, J. M., Gessner, R., Kleinert, A., Koopman, R., Langen, J., López-Puertas, M., Mosner, P., Nett, H., Oelhaf, H., Perron, G., Remedios, J., Ridolfi, M., Stiller, G., and Zander, R.: MIPAS: an instrument for atmospheric and climate research, Atmos. Chem. Phys., 8, 2151-2188, doi:10.5194/acp-8-2151-2008, 2008.

Fishman, J., Bowman, K. W., Burrows, J. P., Richter, A., Chance, K. V., Edwards, D. P., Martin, R. V., Morris, G. A., Pierce, R. B., Ziemke, J. R., Al-Saadi, J. A., Creilson, J. K., Schaack, T. K., and Thompson, A. M.: Remote sensing of tropospheric pollution from space, B. Am. Meteorol. Soc., 89, 805821, 2008.

Fu, D., Worden, J. R., Liu, X., Kulawik, S. S., Bowman, K. W., and Natraj, V.: Characterization of ozone profiles derived from Aura TES and OMI radiances, Atmos. Chem. Phys., 13, 3445-3462, doi:10.5194/acp-13-3445-2013, 2013.

Gorshelev, V., Serdyuchenko, A., Weber, M., Chehade, W., and Burrows, J. P.: High spectral resolution ozone absorption crosssections - Part 1: Measurements, data analysis and comparison with previous measurements around $293 \mathrm{~K}$, Atmos. Meas. Tech. 7, 609-624, doi:10.5194/amt-7-609-2014, 2014.

Hollingsworth, A., Engelen, R. J., Textor, C., Benedetti, A., Boucher, O., Chevallier, F., Dethof, A., Elbern, H., Eskes, H., Flemming, J., Granier, C., Kaiser, J. W., Morcrette, J.-J., Rayner, P., Peuch, V.-H., Rouil, L., Schultz, M. G., Simmons, A. J., and Consortium, G.: Toward a monitoring and forecasting system for atmospheric composition: the GEMS project, B. Am. Meteorol. Soc., 89, 1147-1164, doi:10.1175/2008BAMS2355.1, 2008. 
Holloway, A. M. and Wayne, R. P.: Atmospheric Chemistry, ISBN 978-1-84755-807-7, Published by the Royal Society of Chemistry, Cambridge, UK, 2010.

Höpfner, M., Stiller, G. P., Kuntz, M., von Clarmann, T., Echle, G., Funke, B., Glatthor, N., Hase, F., Kemnitzer, H., and Zorn, S.: The Karlsruhe optimized and precise radiative transfer algorithm, Part II: Interface to retrieval applications, Optical Remote Sensing of the Atmosphere and Clouds, Vol. 3501, 186-195, 1998.

IGACO: The Changing Atmosphere: an Integrated Global Atmospheric Chemistry Observation theme for the IGOS Partnership, ESA SP-1282, GAW Rep 159, WMO/TD-1235, 72 pp., available at: ftp://ftp.wmo.int/Documents/PublicWeb/arep/gaw/ gaw159.pdf (last access: July 2014), 2004.

Josse, B., Simon, P., and Peuch, V.: Radon global simulations with the multiscale chemistry and transport model MOCAGE, Tellus B, 56, 339-356, 2004.

Koelemeijer, R., de Haan, J., and Stammes, P.: A database of spectral surface reflectivity in the range $335-772 \mathrm{~nm}$ derived from 5.5 years of GOME observations, J. Geophys. Res.-Atmos., 108, 4070, doi:10.1029/2002JD002429, 2003.

Laan, E., de Vries, J., Kruizinga, B., Visser, H., Levelt, P., van den Oord, G., Maelkki, A., Leppelmeier, G., and Hilsenrath, E.: Ozone Monitoring with the OMI Instrument, in: Imaging Spectrometry VI. Proceedings of the Society of Photo-Optical Instrumentation Engineers (SPIE), edited by: Descour, M. R. and Shen, S. S., Vol. 4132, 334-343, Conference on Imaging Spectrometry VI, SAN DIEGO, CA, 31 July-2 August 2000, 2000.

Lahoz, W., Brugge, R., Jackson, D., Migliorini, S., Swinbank, R., Lary, D., and Lee, A.: An observing system simulation experiment to evaluate the scientific merit of wind and ozone measurements from the future SWIFT instrument, Q. J. Roy. Meteor. Soc., 131, 503-523, 2005.

Lahoz, W. A., Peuch, V. H., Orphal, J., Attie, J. L., Chance, K., Liu, X., Edwards, D., Elbern, H., Flaud, J. M., Claeyman, M., and El Amraoui, L.: Monitoring air quality from space: the case for the geostationay platform, B. Am. Meteorol. Soc., 93, 221233, 2012.

Landgraf, J. and Hasekamp, O. P.: Retrieval of tropospheric ozone: the synergistic use of thermal infrared emission and ultraviolet reflectivity measurements from space, J. Geophys. Res.-Atmos., 112, D08310, doi:10.1029/2006JD008097, 2007.

Lee, S., Hong, Y., Song, C.-K., Lee, J., Choi, W.-J., Kim, D., Moon, K.-J., and Kim, J.: Plan of Korean geostationary environment satellite over Asia-Pacific region, Geophys. Res. Abstr., EGU-2010-7595-1, EGU General Assembly 2010, Vienna, Austria, 2010.

Lefevre, F., Brasseur, G., Folkins, I., Smith, A., and Simon, P.: Chemistry of the 1991-1992 stratospheric winter - 3dimensional model simulations, J. Geophys. Res.-Atmos., 99, 8183-8195, 1994.

Liu, X., Chance, K., Sioris, C., Spurr, R., Kurosu, T., Martin, R., and Newchurch, M.: Ozone profile and tropospheric ozone retrievals from the Global Ozone Monitoring Experiment: algorithm description and validation, J. Geophys. Res.-Atmos., 110, D20307, doi:10.1029/2005JD006240, 2005.

Liu, X., Chance, K., Sioris, C. E., and Kurosu, T. P.: Impact of using different ozone cross sections on ozone profile retrievals from Global Ozone Monitoring Experiment (GOME) ultraviolet mea- surements, Atmos. Chem. Phys., 7,3571-3578, doi:10.5194/acp7-3571-2007, 2007.

Louis, J.: Parametric model of vertical eddy fluxes in the atmosphere, Bound.-Lay. Meteorol., 17, 187-202, 1979.

Malicet, J., Daumont, D., Charbonnier, J., Parisse, C., Chakir, A., and Brion, J.: Ozone UV spectroscopy, II. Absorption crosssections and temperature dependence, J. Atmos. Chem., 21, 263 273, 1995.

Marquardt, D.: An algorithm for least-squares estimation of nonlinear parameters, J. Soc. Ind. Appl. Math., 11, 431-441, 1963.

Martin, R. V.: Satellite remote sensing of surface air quality, Atmos. Environ., 42, 7823-7843, 2008.

Masutani, M., Woollen, J. S., Lord, S. J., Emmitt, G. D., Kleespies, T. J., Wood, S. A., Greco, S., Sun, H., Terry, J., Kapoor, V., Treadon, R., and Campana, K. A.: Observing system simulation experiments at the National Centers for Environmental Prediction, J. Geophys. Res.-Atmos., 115, D07101, doi:10.1029/2009JD012528, 2010.

McNair, L., Harley, R., and Russell, A.: Spatial inhomogeneity in pollutant concentrations, and their implications for air quality model evaluation, Atmos. Environ., 30, 4291-4301, 1996.

Munro, R.: Future EUMETSAT satellite missions, available at: http://www.google.fr/url?sa=t\&rct=j\&q=\&esrc=s\&source= web\&cd=1\&ved=0CDAQFjAA\&url=http://earth.eo.esa.int/ workshops/Volcano/files/EUMETSAT_Future_Missions_ Rose_Munro.pdf\&ei=ZL38UoOjIsfK0QWhnIHADg\&usg= AFQjCNGd0d2yif2GNFysyiSVQYFq2OLxzw\&sig2= BCAruiKsuYdP5ZoIzQ86Ag\&bvm=bv.61190604,d. bGE\&cad=rja (last access: February 2014), 2011.

Natraj, V., Liu, X., Kulawik, S., Chance, K., Chatfield, R., Edwards, D. P., Eldering, A., Francis, G., Kurosu, T., Pickering, K., Spurr, R., and Worden, H.: Multi-spectral sensitivity studies for the retrieval of tropospheric and lowermost tropospheric ozone from simulated clear-sky GEO-CAPE measurements, Atmos. Environ., 45, 7151-7165, 2011.

Orphal, J., Bergametti, G., Beghin, B., Hébert, J.-P., Steck, T., and Flaud, J.-M.: Monitoring tropospheric pollution using infrared spectroscopy from geostationary orbit, C. R. Phys., 6, 888-896, 2005.

Peuch, V.-H., Attié, J.-L., Claeyman, M., El Amraoui, L., Ricaud, P., Semane, N., Massart, S., Piacentini, A., Cariolle, D., Flaud, J.-M., Bergametti, G., Cantié, R., Pasternak, F., Lehors, L., von Clarmann, T., Höpfner, M., and Orphal, J.: Data Assimilation Experiments within the POGEQA Project, EOS T. Am. Geophys Union, 90 (Fall Meeting Suppl.), Abstract A51M-05, 2009.

Peuch, V.-H., Orphal, J., Attié, J.-L., et al.: MAGEAQ: Monitoring the Atmosphere from Geostationary Orbit for European Air Quality, Earth Explorer Opportunity Mission EE-8 Proposal, ESA, 185 pp., 2010.

Richter, A., Wittrock, F., Weber, M., and Burrows, J. P.: Evaluating the potential of GOME-2 ozone column retrievals in the Chappuis bands, EGU General Assembly 2012, held 22-27 April 2012 in Vienna, Austria, p. 1747, 2012.

Rodgers, C. D.: Inverse Methods for Atmospheric Sounding: Theory and Practice, World Scientific, 2000.

Rothman, L. S., Jacquemart, D., Barbe, A., Chris Benner, D., Birk, M., Brown, L. R., Carleer, M. R., Chackerian Jr., C., Chance, K., Coudert, L. H., Dana, V., Devi, V. M., Flaud, J.-M., Gamache, R. R., Goldman, A., Hartmann, J.-M., Jucks, K. W., 
Maki, A. G., Mandin, J.-Y., Massie, S. T., Orphal, J., Perrin, A., Rinsland, C. P., Smith, M. A. H., Tennyson, J., Tolchenov, R. N., Toth, R. A., Vander Auwera, J., Varanasi, P., and Wagner, G.: The HITRAN 2004 molecular spectroscopic database, J. Quant. Spectrosc. Ra., 96, 139-204, 2005.

Rothman, L. S., Gordon, I. E., Barbe, A., Benner, D. C., Bernath, P. E., Birk, M., Boudon, V., Brown, L. R., Campargue, A., Champion, J.-P., Chance, K., Coudert, L. H., Dana, V., Devi, V. M., Fally, S., Flaud, J.-M., Gamache, R. R., Goldman, A., Jacquemart, D., Kleiner, I., Lacome, N., Lafferty, W. J., Mandin, J.-Y., Massie, S. T., Mikhailenko, S. N., Miller, C. E., Moazzen-Ahmadi, N., Naumenko, O. V., Nikitin, A. V., Orphal, J., Perevalov, V. I., Perrin, A., Predoi-Cross, A., Rinsland, C. P., Rotger, M., Simeckova, M., Smith, M. A. H., Sung, K., Tashkun, S. A., Tennyson, J., Toth, R. A., Vandaele, A. C., and Vander Auwera, J.: The HITRAN 2008 molecular spectroscopic database, J. Quant. Spectrosc. Ra., 110, 533$572,2009$.

Schutgens, N. and Stammes, P.: A novel approach to the polarization correction of spaceborne spectrometers, J. Geophys. Res.Atmos., 108, 4229, doi:10.1029/2002JD002736, 2003.

Spurr, R.: Linearized pseudo-spherical scalar and vector discrete ordinate radiative transfer models for use in remote sensing retrieval problems, Light Scattering Reviews, 229-275, 2008.

Spurr, R. J. D.: VLIDORT: a linearized pseudo-spherical vector discrete ordinate radiative transfer code for forward model and retrieval studies in multilayer multiple scattering media, J. Quant. Spectrosc. Ra., 102, 316-342, 2006.
Stiller, G., von Clarmann, T., Funke, B., Glatthor, N., Hase, F., Höpfner, M., and Linden, A.: Sensitivity of trace gas abundances retrievals from infrared limb emission spectra to simplifying approximations in radiative transfer modelling, J. Quant. Spectrosc. Ra., 72, 249-280, 2002.

Stockwell, W., Kirchner, F., Kuhn, M., and Seefeld, S.: A new mechanism for regional atmospheric chemistry modeling, J. Geophys. Res.-Atmos., 102, 25847-25879, 1997.

Timmermans, R. M. A., Schaap, M., Elbern, H., Siddans, R., Tjemkes, S., Vautard, R., and Builtjes, P.: An Observing System Simulation Experiment (OSSE) for Aerosol Optical Depth from Satellites, J. Atmos. Ocean. Tech., 26, 2673-2682, doi:10.1175/2009JTECHA1263.1, 2009.

Tjemkes, M. A., Patterson, T., Rizzi, R., Shephard, M. W., Clough, S. A., Matricardi, M., Haigh, J., Höpfner, M., Payan, S., Trotsenko, A., Scott, N., Rayer, P., Taylor, J. P., Clerbaux, C., Strow, L. L., DeSouza-Machado, S., Tobin, D., and Knuteson, R.: The ISSWG line-by-line intercomparison experiment, J. Quant. Spectrosc. Ra., 77, 433-453, 2003.

Worden, J., Liu, X., Bowman, K., Chance, K., Beer, R., Eldering, A., Gunson, M., and Worden, H.: Improved tropospheric ozone profile retrievals using OMI and TES radiances, Geophys. Res. Lett., 34, L01809, doi:10.1029/2006GL027806, 2007.

Zoogman, P., Jacob, D. J., Chance, K., Zhang, L., Le Sager, P., Fiore, A. M., Eldering, A., Liu, X., Natraj, V., and Kulawik, S. S.: Ozone air quality measurement requirements for a geostationary satellite mission, Atmos. Environ., 45, 7143-7150, 2011. 